\title{
Morphology of copper nanoparticles in a nitrogen atmosphere: A first-principles investigation
}

\author{
Aloysius Soon, ${ }^{1, *}$ Lindee Wong, ${ }^{1}$ Bernard Delley, ${ }^{2}$ and Catherine Stampfl ${ }^{1}$ \\ ${ }^{1}$ School of Physics, The University of Sydney, Sydney, New South Wales 2006, Australia \\ ${ }^{2}$ Paul-Scherrer-Institut, WHGA/123, CH-5232 Villigen PSI, Switzerland
}

(Received 26 December 2007; published 24 March 2008; publisher error corrected 28 March 2008)

\begin{abstract}
We perform first-principles density-functional-theory calculations to determine the stability and associated physical and electronic properties of different adsorption phases of $\mathrm{N}$ on $\mathrm{Cu}(100)$ and $\mathrm{Cu}(110)$ substrates for coverages ranging from 0.125 to 1 monolayer (ML). For $\mathrm{N}$ on $\mathrm{Cu}(100)$, we consider adsorption in fourfold hollow sites while for $\mathrm{N}$ on $\mathrm{Cu}$ (110), we consider various adsorption sites including $\mathrm{N}$-induced missing-row surface reconstructions and the surface nitridelike, "pseudo-(100)" reconstruction. We report the atomic and electronic structure and compare with analogous results for $\mathrm{N} / \mathrm{Cu}$ (111). By combining results from our previous study of the $\mathrm{N} / \mathrm{Cu}(111)$ system with the current investigations, we predict the possible morphology of a $\mathrm{Cu}$ crystal in different nitrogen environments by performing a Wulff construction at appropriate chemical potentials of nitrogen. We also find that all low-energy $\mathrm{N} / \mathrm{Cu}$ surface structures-namely, $\mathrm{Cu}(100)-c(2$ $\times 2$ )- $\mathrm{N}$ and the surface nitrides found on $\mathrm{Cu}(110)$ and $\mathrm{Cu}(111)$ - share a common geometric feature: i.e., surface nanopatterns resembling 1 atomic layer of $\mathrm{Cu}_{3} \mathrm{~N}(100)$. These nanopatterned structures exist for a narrow range of nitrogen chemical potentials before the onset of bulk $\mathrm{Cu}_{3} \mathrm{~N}$, unless kinetically hindered. This qualitative behavior of the predicted formation of thin-surface nitridelike structures prior to the bulk nitride material is very similar to that for transition-metal surfaces in an oxygen atmosphere, where surface oxidelike structures are predicted to be thermodynamically stable prior to bulk oxide formation.
\end{abstract}

DOI: $10.1103 /$ PhysRevB.77.125423

PACS number(s): 68.35.Md, 68.35.B-, 68.35.-p, 05.70.Np

\section{INTRODUCTION}

Understanding the interaction between $\mathrm{N}$ and $\mathrm{Cu}$ surfaces is important as copper-based catalysts are widely used in systems containing nitrogen-for example, the reduction and decomposition of nitrogen oxides ${ }^{1-3}$ and the oxydehydrogenation (i.e., oxidation) of ammonia. ${ }^{4,5}$ With regard to the oxidation of ammonia, $\mathrm{NH}_{3}$, it has been proposed that copper oxide is not the active material as had been reported earlier, ${ }^{5}$ but copper nitride or a mixed $\mathrm{Cu}_{3} \mathrm{~N} / \mathrm{Cu}_{2} \mathrm{O}$ structure. ${ }^{4}$ Furthermore, N-modified $\mathrm{Cu}(100), \mathrm{Cu}$ (110), and $\mathrm{Cu}$ (111) surfaces have been used in the nanostructure fabrication of Ag nanowires and Co nanowires and nanodots, ${ }^{6-9}$ often acting as a template for well-controlled patterned growth of these low-dimensional metallic structures.

These applications have motivated a number of experimental studies of nitrogen adsorption on low-index copper surfaces. Under ambient temperatures and pressures, molecular nitrogen does not interact with $\mathrm{Cu}$ surfaces, due to the strong nitrogen-nitrogen bond, so the adsorption of nitrogen on $\mathrm{Cu}$ (100), $\mathrm{Cu}$ (110), and $\mathrm{Cu}$ (111) surfaces has been achieved typically by nitrogen-ion bombardment. ${ }^{10-12}$ These experimental investigations have resulted in a number of observed adsorption phases, from simple chemisorption to complex surface nitride structures, which have a thickness on the nanometer or subnanometer scale. ${ }^{13}$

For the $\mathrm{N} / \mathrm{Cu}(100)$ system, both experimental ${ }^{6-9,12,14-16}$ and density-functional theory ${ }^{17,18}$ (DFT) studies have confirmed that $\mathrm{N}$ chemisorbs on $\mathrm{Cu}(100)$ in the fourfold hollow $(4 \mathrm{FH})$ sites, forming a $\mathrm{Cu}(100)-p(2 \times 2)-2 \mathrm{~N}$ structure, otherwise (and hereafter) known as the $\mathrm{Cu}(100)-c(2 \times 2)-\mathrm{N}$ phase, with 0.5 monolayer (ML) coverage at saturation [see Fig. 1(b)]. In Fig. 1(a), we also show a lower-coverage $p(2 \times 2)-\mathrm{N}(0.25-\mathrm{ML})$ structure. Interestingly, for nitrogen coverages $\Theta_{\mathrm{N}}$ in the range of $\sim 0.25-0.5 \mathrm{ML}$, experimentally it is found that nitrogen induces the formation of periodic, square "nano-grid"-like islands (typically $5 \mathrm{~nm}$ $\times 5 \mathrm{~nm}$ ), where the local atomic structure of these nano-islands is identical to the $\mathrm{Cu}(100)-c(2 \times 2)-\mathrm{N}$ structure. ${ }^{6-9,12,19-22}$ To our knowledge, this is the only ordered phase that has been reported for the $\mathrm{N} / \mathrm{Cu}(100)$ system and it is found to be stable up to $600 \mathrm{~K}^{6-9}$

From a theoretical point of view, a recent DFT study on the atomic structure and energetics of this experimentally observed $\mathrm{Cu}(100)-c(2 \times 2)-\mathrm{N}$ structure has been performed using the projector-augmented-wave (PAW) method and the generalized gradient approximation (GGA) ${ }^{17}$ They investigated three different adsorption models: namely, (i) with $\mathrm{N}$ at the 4FH site, (ii) with $\mathrm{N}$ still at the $4 \mathrm{FH}$ site but alternate rows of surface $\mathrm{Cu}$ atoms displaced (out of plane) in the direction away from the surface (we refer the reader to Ref. 17 for details), and (iii) with $\mathrm{N}$ at the top site. It was found that the most stable absorption phase consists of nitrogen atoms positioned in the $4 \mathrm{FH}$ site (i.e., the first model described above), with an adsorption energy of $4.88 \mathrm{eV}$ per nitrogen atom, giving support to experimental observation.

In an earlier DFT-GGA plane-wave pseudopotential study,${ }^{18}$ Yoshimoto and Tsuneyuki investigated the formation of these interesting self-organizing surface structures, attempting to understand the driving force behind their stability. They found the surface nitrogen adatom interaction on the $\mathrm{Cu}(100)$ surface is attractive, leading to the formation of these $c(2 \times 2)-\mathrm{N}$ nanoislands as suggested experimentally. In addition, they also studied the diffusion pathways of $\mathrm{N}$ on $\mathrm{Cu}$ (100) and found the diffusion barrier for $\mathrm{N}$ via the bridge site to be $1.5-1.7 \mathrm{eV}$. Scanning tunneling microscopy (STM) images of the $\mathrm{Cu}(100)-c(2 \times 2)-\mathrm{N}$ structure were simulated and are in line with experimental STM images ${ }^{6}$ where bright 


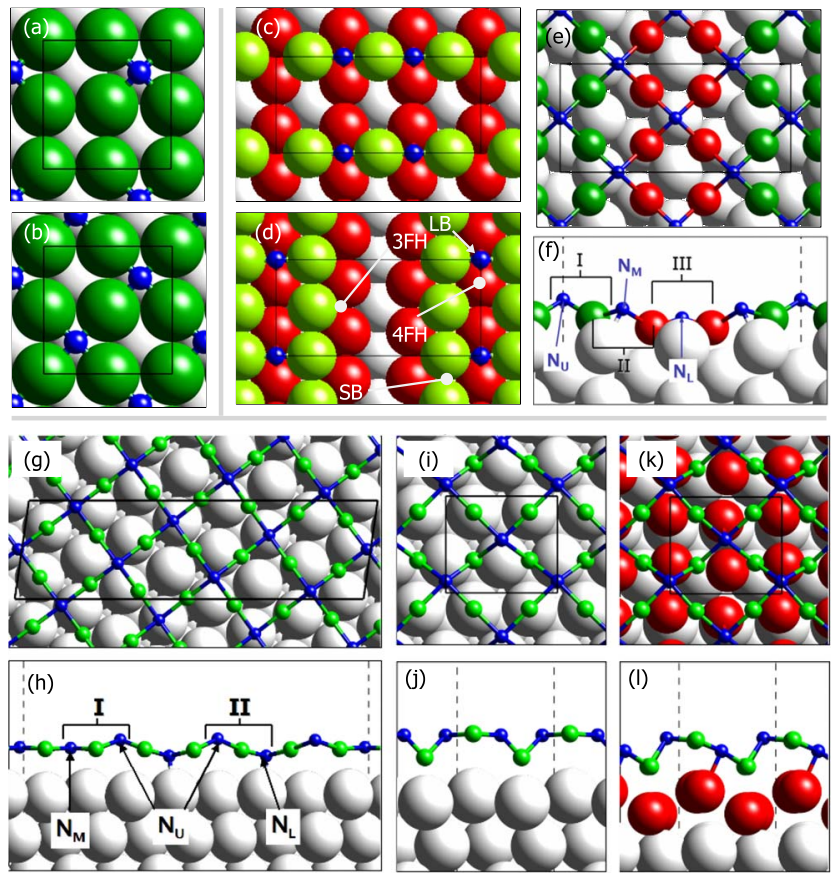

FIG. 1. (Color online) Atomic geometries of various $\mathrm{N} / \mathrm{Cu}$ surface structures: (a) and (b) show the top view of $\mathrm{Cu}$ (100)-p (2 $\times 2)-\mathrm{N}$ and $\mathrm{Cu}(100)-c(2 \times 2)-\mathrm{N}$, respectively, and that of $\mathrm{Cu}(110)-p(2 \times 3)-2 \mathrm{~N}$ and $\mathrm{Cu}(110)-p(2 \times 3)-\mathrm{N}$ are depicted in $(\mathrm{c})$ and (d), respectively. For $\mathrm{Cu}(110)-p(2 \times 3)-4 \mathrm{~N}$, the top and side views are shown in (e) and (f). Top views of (g) the "16" structure, (i) the " 4 " structure for one $\mathrm{Cu}$-layer reconstruction (i.e., 1L-“4"), and $(\mathrm{k})$ the " 4 " structure for the two $\mathrm{Cu}$-layer reconstruction (i.e., 2L-“4") [with the second-layer $\mathrm{Cu}$ atoms highlighted as large dark (red) spheres]. (h), (j), and (l) show the corresponding side views of these structures. In all figures lighter large (green) spheres represent top-layer $\mathrm{Cu}$ atoms (i.e., $\mathrm{Cu}_{1 \mathrm{~L}}$ ), darker large (red) spheres represent second-layer $\mathrm{Cu}$ atoms (i.e., $\mathrm{Cu}_{2 \mathrm{~L}}$ ), and dark small (blue) spheres represent $\mathrm{N}$ atoms, with the exception in (e) and (f) where the lighter (green) and darker (red) large spheres are used to differentiate the slight rumping seen in the surface nitride layer. The $\mathrm{Cu}$ substrate atoms are shown in pale (gray) large spheres. Note that in (g)-(1), the top reconstructed $\mathrm{Cu}$ layer is shown in smaller darker (green) spheres for clarity.

features of the $\mathrm{Cu}(100)-c(2 \times 2)-\mathrm{N}$ structure corresponded to $\mathrm{N}$ adatoms.

Concerning nitrogen adsorption on $\mathrm{Cu}$ (110), early lowenergy electron diffraction (LEED) studies find a $\mathrm{Cu}(110)-p(2 \times 3)-4 \mathrm{~N}$ surface nitridelike structure forms over the substrate, consisting of an almost square $\mathrm{Cu}(100)-c(2 \times 2)-\mathrm{N}$ mesh. ${ }^{23-29}$ This structure has a nitrogen coverage of $0.66 \mathrm{ML}$ and is shown in Figs. 1(e) and 1(f). The $\mathrm{Cu}(110)-p(2 \times 3)-4 \mathrm{~N}$ structure is structurally reconstructed and geometrically different from simple chemisorbed phases. For this work, it will be referred to as a surface nitride.

Other surface reconstruction models have been proposed in the literature for the $(2 \times 3)$ phase, including a "[001] missing-row structure," 30 which we will refer to hereafter as the " $\mathrm{Cu}$ (110)- $p(2 \times 3)-2 \mathrm{~N}$ " model, and a "[110] missingrow structure," 31 which we will refer to hereafter as the "Cu (110)- $p(2 \times 3)-\mathrm{N} "$ model. $\mathrm{Cu}(110)-p(2 \times 3)-2 \mathrm{~N}$ is shown in Fig. 1(c), with a top layer $\mathrm{Cu}$ row in the [001] direction missing and two nitrogen atoms adsorbed in the long-bridge (LB) site, resulting in a coverage of $0.33 \mathrm{ML}$. For the $\mathrm{Cu}(110)-p(2 \times 3)-\mathrm{N}$ model, a row of $\mathrm{Cu}$ atoms in the [110] direction is removed from the $\mathrm{Cu}$ (110) surface, with a nitrogen atom adsorbed in the LB site, resulting in a coverage of $0.17 \mathrm{ML}$. This structure is shown in Fig. 1(d). To our knowledge, other than the $p(2 \times 3)$ phase, no other ordered surface structures have been reported for $\mathrm{N} / \mathrm{Cu}(110)$. To date, there have also been no first-principles investigations performed for $\mathrm{N} / \mathrm{Cu}$ (110).

With regard to nitrogen adsorption on $\mathrm{Cu}$ (111), experimental evidence shows that a surface nitride structure forms. This surface nitride is proposed to consist of nitrogen atoms adsorbed in the fourfold hollow sites of a pseudo-(100) reconstruction of the $\mathrm{Cu}(111)$ surface with a $c(2 \times 2)$ periodicity, i.e., a $\mathrm{Cu}(100)-c(2 \times 2)-\mathrm{N}$-like mesh forms over the $\mathrm{Cu}$ (111) substrate. ${ }^{10,32-38}$ A STM study has proposed that the above-mentioned pseudo-(100) phase on $\mathrm{Cu}$ (111) forms a $(25 \times 7 \sqrt{3})$ rectangular commensurate layer on the substrate. ${ }^{10}$

Our recent DFT study of nitrogen adsorption on $\mathrm{Cu}(111)$ (Ref. 39) is consistent with experimental results, ${ }^{10,32-38}$ finding models of the pseudo-(100) reconstruction to be both energetically preferred over other adsorption structures considered, such as on-surface adsorption at fcc or hcp threefold hollow sites, as well as subsurface adsorption. The most favorable model of the surface nitride reconstruction that we considered consisted of a $\left(\begin{array}{cc}2 & 0 \\ -3 & 8\end{array}\right)$ surface unit cell, which will be referred to as the "16" structure [see Figs. 1(g) and 1(h)], since the area of this cell is 16 times larger than that of the primitive $\mathrm{Cu}$ (111) unit cell. In addition, we also investigated surface nitride structures with a smaller periodicity: namely, the "4" structure - one with only the outermost layer of $\mathrm{Cu}$ atoms reconstructed, 1L-"4" [Figs. 1(i) and 1(j)] and another with the two outermost $\mathrm{Cu}$ layers reconstructed, 2L-" 4 " [Figs. 1(k) and 1(1)]. These structures have 4 times the area of the primitive $\mathrm{Cu}$ (111) unit cell and are energetically less favorable than the "16" structure. Further details can be found in Ref. 39.

In the present work we present a DFT study of the chemisorbed phases of nitrogen on $\mathrm{Cu}(100)$ and $\mathrm{Cu}$ (110) surfaces, where we consider coverages ranging from 0.125 to $1 \mathrm{ML}$. For the N/Cu (110) system, we include surface reconstructions involving missing $\mathrm{Cu}$ rows in the [110] and [001] directions-i.e., the $\mathrm{Cu}(110)-p(2 \times 3)-\mathrm{N}$ and $\mathrm{Cu}(110)-p(2 \times 3)-2 \mathrm{~N}$ structures, respectively, as well as a reconstructed $\mathrm{Cu}(110)-p(2 \times 3)-4 \mathrm{~N}$ surface nitridelike structure. Finally, chemisorption structures with $\mathrm{N}$ in the 4FH, 3FH (i.e., pseudo-threefold-hollow), (LB), and short bridge (SB) sites, on both the ideal $\mathrm{Cu}(110)$ surface and that with a row of $\mathrm{Cu}$ atoms missing in the [110] direction, are considered. For $\mathrm{Cu}$ (100), only the most favorable 4FH site is investigated. For all structures, we examine the electronic properties, atomic geometries, and their relative energetic stabilities. The findings for the N/Cu (100) and N/Cu (110) structures are compared with the results of our previous study of nitrogen adsorption on $\mathrm{Cu}(111) .{ }^{39}$

Knowing that the morphology of a nanoparticle could be a factor responsible for their physical and chemical properties (and thus functionality), we proceed to investigate the 

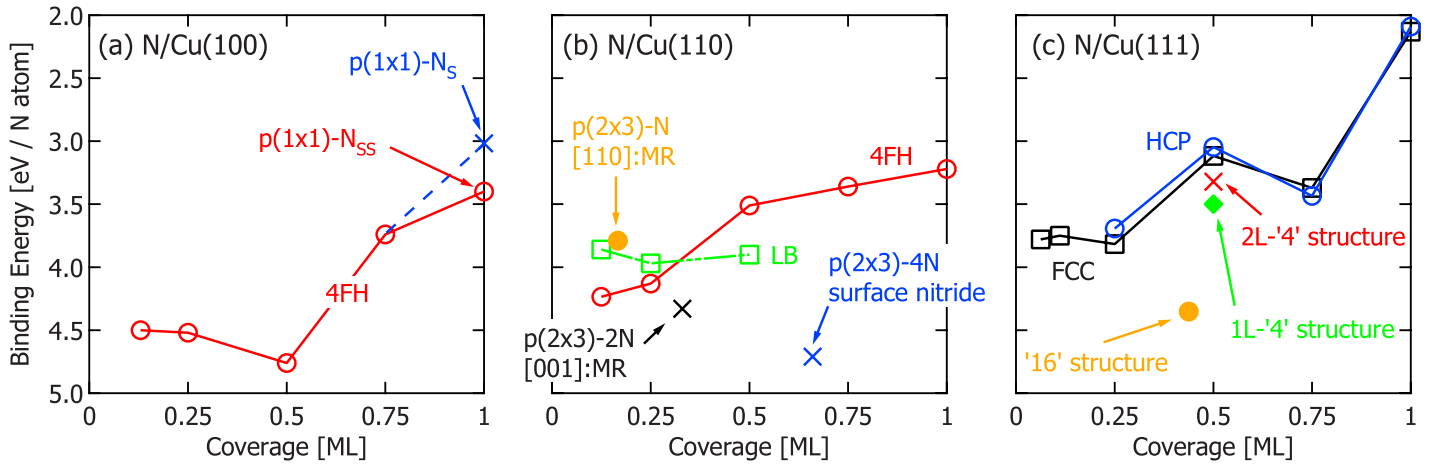

FIG. 2. (Color online) Calculated average binding energies of $\mathrm{N}$ on (a) $\mathrm{Cu}(100)$, (b) $\mathrm{Cu}(110)$, and (c) $\mathrm{Cu}$ (111), for various coverages of nitrogen and reconstructions. The solid and dashed lines connecting the calculated binding energies are used to guide the eye. In (a), $p(1 \times 1)-\mathrm{N}_{\mathrm{S}}$ is the full monolayer $\mathrm{N} / \mathrm{Cu}(100)$ structure with nitrogen atoms adsorbed on-surface, while $p(1 \times 1)$ - $\mathrm{N}_{\mathrm{SS}}$ is that with nitrogenatom subsurface. The values for (c) are taken from Ref. 39.

possible "nanomorphology" of $\mathrm{Cu}$ particles under various nitrogen atmospheres. In particular, having obtained accurate DFT-derived surface energies of these N/Cu low-index surface structures, we perform a Wulff construction ${ }^{40}$ at selected values of the nitrogen-atom chemical potential and explore how the Wulff polygon changes from nitrogen-lean to nitrogen-rich conditions.

\section{METHODOLOGY}

The DFT calculations are performed with the $\mathrm{DMol}^{3}$ code, using the generalized gradient approximation (GGA) for the exchange-correlation functional due to Perdew, Burke, and Ernzerhof (PBE). ${ }^{41} \mathrm{DMol}^{3}$ is a numerical implementation which uses a highly efficient local orbital basis set. Further details about the code can be found elsewhere. ${ }^{42,43}$

The $\mathrm{Cu}(100)$ substrate is modeled using a supercell, with nitrogen coverage on both sides of a 9-atomic-layer slab, while the $\mathrm{Cu}$ (110) substrate is modeled with 11 atomic layers, preserving inversion symmetry in both surface models. The vacuum region between repeated slabs is $30 \AA$. The double- $\zeta$ plus polarization (DNP) basis set and a real space cutoff of 9 bohrs are used for all calculations. Brillouin-zone integrations are performed using a $(12 \times 12 \times 1)$ MonkhorstPack grid for the $\mathrm{Cu}(100)(1 \times 1)$ surface unit cell, and equivalent k-point sampling is used for the larger cells. For the $\mathrm{Cu}(110)$ surface, a $(12 \times 6 \times 1)$ grid is used for the $(1$ $\times 1)$ surface unit cell and equivalent sampling for larger cells-for example, a $(6 \times 2 \times 1)$ grid for the $(2 \times 3)$ surface cell. For all calculations, the inner three atomic layers of each slab are fixed and all other atoms are relaxed until the forces are less than $0.3 \mathrm{mHa} / \mathrm{bohr}(0.015 \mathrm{eV} / \AA)$. These parameters were chosen to ensure that calculated energies are well converged, with an estimated numerical uncertainty of less than $1 \mathrm{mHa}$ (see the Appendix).

The calculated average binding energies with respect to the free nitrogen atom (per $\mathrm{N}$ atom) are presented in Fig. 2. The binding energy is calculated according the formula

$$
E_{b}^{\mathrm{N}}=-\frac{1}{N_{\mathrm{N}}}\left(E_{\mathrm{N} / \mathrm{Cu}}-E_{\mathrm{Cu}}^{\mathrm{slab}}-\Delta N_{\mathrm{Cu}} E_{\mathrm{Cu}}-N_{\mathrm{N}} E_{\mathrm{N}}\right),
$$

where $N_{\mathrm{N}}$ and $\Delta N_{\mathrm{Cu}}$ are, respectively, the number of nitrogen atoms in the $\mathrm{N} / \mathrm{Cu}$ system and the difference in the number of $\mathrm{Cu}$ atoms between the $\mathrm{N} / \mathrm{Cu}$ system and the clean surface slab. $E_{\mathrm{N} / \mathrm{Cu}}$ is the total energy of the N/Cu system, $E_{\mathrm{Cu}}^{\text {slab }}$ the energy of the clean slab, $E_{\mathrm{Cu}}$ the energy of a $\mathrm{Cu}$ atom in bulk $\mathrm{Cu}$, and $E_{\mathrm{N}}$ the energy of a free nitrogen atom from a spinpolarized calculation. The term $\Delta N_{\mathrm{Cu}} E_{\mathrm{Cu}}$ is only required when the total number of $\mathrm{Cu}$ atoms on the surface is different from that of the clean substrate, as is the case for $\mathrm{Cu}$ (110) surface reconstructions and the surface nitride structures on both $\mathrm{Cu}$ (110) and $\mathrm{Cu}$ (111). A positive binding energy indicates that the adsorption is exothermic, and a larger binding energy indicates a more stable structure.

Using concepts from " $a b$ initio atomistic thermodynamics," 44 we determine the relative stability of the considered structures over a range of chemical potentials for the nitrogen atom. In particular, we calculate the Gibbs free energy of adsorption,

$$
\Delta G(T, p)=\frac{1}{2 A}\left(G_{\mathrm{N} / \mathrm{Cu}}-G_{\mathrm{Cu}}^{\mathrm{slab}}-\Delta N_{\mathrm{Cu}} \mu_{\mathrm{Cu}}-N_{\mathrm{N}} \mu_{\mathrm{N}}\right),
$$

where $G_{\mathrm{N} / \mathrm{Cu}}$ and $G_{\mathrm{Cu}}^{\text {slab }}$ are the Gibbs free energies of the $\mathrm{N} / \mathrm{Cu}$ system and the clean surface, respectively. $A$ is the surface area of the $\mathrm{N} / \mathrm{Cu}$ structure, and $\mu_{\mathrm{N}}$ and $\mu_{\mathrm{Cu}}$ are the chemical potentials of the nitrogen and copper atoms. The term $\Delta N_{\mathrm{Cu}} \mu_{\mathrm{Cu}}$ represents the cost of interchanging the $\mathrm{Cu}$ species with a reservoir of $\mathrm{Cu}$ atoms with chemical potential $\mu_{\mathrm{Cu}}$. This reservoir is taken to be bulk $\mathrm{Cu}$, with which the surface is assumed to be in equilibrium. For more details, we refer to Refs. 44 and 45. By incorporating Eq. (1) into Eq. (2), we simplify Eq. (2) to give

$$
\Delta G\left(\Delta \mu_{\mathrm{N}}\right) \approx \frac{1}{2 A}\left(-N_{\mathrm{N}} E^{\mathrm{N}_{b}-N_{\mathrm{N}} \Delta \mu_{\mathrm{N}}}\right),
$$

where the nitrogen chemical potential is now measured with respect to the free nitrogen atom, $\Delta \mu_{N}=\mu_{N}-E_{N}$, and we neglect contributions due to vibrations and the pressure-volume term. $^{44}$ 


\section{RESULTS AND DISCUSSION}

\section{A. $\mathrm{Cu}(100)$ and $\mathrm{Cu}(110)$ surfaces, bulk $\mathrm{Cu}$, and the $\mathrm{N}_{2}$ molecule}

The properties of bulk $\mathrm{Cu}$, clean $\mathrm{Cu}$ surfaces, and the $\mathrm{N}_{2}$ molecule are first considered to ensure that the DFT calculations provide accurate results. The properties of these systems are well known from experimental results as well as from other $a b$ initio calculations.

The calculated lattice constant of bulk $\mathrm{Cu}$ (neglecting zero-point vibrations) is $3.64 \AA$, which is in good agreement with the established experimental value of $3.61 \AA .{ }^{46}$ The Brillouin-zone integration for bulk $\mathrm{Cu}$ is performed using a $(12 \times 12 \times 12)$ Monkhorst-Pack grid for a $(1 \times 1 \times 1)$ conventional cell with real-space radius cutoff of 9 bohrs. The computed bulk modulus and cohesive energy (taking into account the spin-polarization energy for the free $\mathrm{Cu}$ atom) are $136 \mathrm{GPa}$ and $3.45 \mathrm{eV}$, which are in excellent agreement with the experimental values of $137 \mathrm{GPa}$ and $3.49 \mathrm{eV},{ }^{46}$ respectively. The minor overestimation of the lattice constant and the underestimation of the bulk modulus are also observed in analogous studies of other transition metals. ${ }^{47-49}$

For the clean $\mathrm{Cu}$ (100) surface, the obtained interlayer relaxations $\Delta_{i j}=\left(d_{i j}-d\right) / d \times 100 \%$ between layers $i$ and $j$, with respect to the bulk spacing $d=1.82 \AA$, are $\Delta_{12}=$ $-2.3 \%$ and $\Delta_{23}=1.0 \%$ for the topmost layers. These results correlate well with other PAW-GGA DFT calculations, ${ }^{17}$ with $\Delta_{12}=-2.6 \%$ and $\Delta_{23}=0.9 \%$ and experimental LEED data, ${ }^{50,51}$ with $\Delta_{12}=-2.1 \%$ and $\Delta_{23}=0.5 \%$. The calculated work function for the clean surface is $4.39 \mathrm{eV}$, which is similar to the reported experimental value of $4.59 \mathrm{eV}$ (Ref. 52) and theoretical value of $4.49 \mathrm{eV}$ (Ref. 17). We note that it is typical that DFT-GGA calculations slightly underestimate the work function of metal surfaces. ${ }^{53}$ The surface energy is calculated to be $0.64 \mathrm{eV}$ per surface unit cell (or $1.5 \mathrm{~J} \mathrm{~m}^{-2}$ ), which is in good agreement with DFT-GGA calculations using the full-potential linearized augmented-plane-wave (FPLAPW) method, ${ }^{54}$ where a value of $0.60 \mathrm{eV}$ is reported. Our calculated surface energy is found to be much lower than the only reported experimental value ${ }^{55}\left(5.5 \mathrm{~J} \mathrm{~m}^{-2}\right.$ or $0.34 \mathrm{eV} / \AA^{2}$ ) but is in line with the theoretical value reported above. ${ }^{54}$

Considering the clean $\mathrm{Cu}(110)$ surface, the obtained interlayer relaxations are $\Delta_{12}=-10.0 \%$ and $\Delta_{23}=3.0 \%$. These results agree with experimental values, ${ }^{56}$ with $\Delta_{12}=$ $-10.0 \% \pm 2.5 \%$ and $\Delta_{23}=0.0 \% \pm 2.5 \%$, and reasonably well with theoretical results using the FP-LAPW method, ${ }^{57}$ yielding $\Delta_{12}=-9.7 \%$ and $\Delta_{23}=3.6 \%$. The work function for the clean surface is calculated to be $4.18 \mathrm{eV}$, which is in reasonable agreement with the reported experimental value of 4.48 $\mathrm{eV}^{52}$ Using the tight-binding linear muffin-tin orbital (TBLMTO) approach and the local density approximation (LDA), the work function of $\mathrm{Cu}$ (110) was found to be 4.80 $\mathrm{eV},{ }^{58}$ which is higher than our calculated value. This is typical of LDA-derived work functions of metals which are generally larger than those calculated with the GGA. ${ }^{53}$ The surface energy is calculated to be $0.97 \mathrm{eV}$ per surface unit cell, which correlates well with the DFT-GGA (FP-LAPW) (Ref. 54) value of $0.901 \mathrm{eV}$. To the best of our knowledge, we did not find the corresponding experimental surface energy value for $\mathrm{Cu}$ (110).

Spin-unrestricted calculations using nonspherical densities are performed to study the nitrogen atom and molecule. To achieve high numerical accuracy, the real-space cutoff for the calculation is increased to 20 bohrs, with the largest basis set available in the $\mathrm{DMol}^{3}$ code. The binding energy of $\mathrm{N}_{2}$ per $\mathrm{N}$ atom is calculated to be $5.19 \mathrm{eV}$, which is typically overbound when compared to the reported experimental value of $4.90 \mathrm{eV} .{ }^{59}$ The bond length and vibrational frequency are $1.11 \AA$ and $2349.6 \mathrm{~cm}^{-1}$, respectively, which compare very well with the reported experimental values of $1.10 \AA$ and $2358.6 \mathrm{~cm}^{-1} .59$

\section{B. Binding energy and structural parameters}

\section{Nitrogen adsorption on $\mathrm{Cu}$ (100)}

For the $\mathrm{Cu}(100)$ surface, chemisorption structures with coverages of $0.125,0.25,0.5,0.75$, and $1 \mathrm{ML}$ are investigated. It is observed that the binding energy increases from 4.50 to $4.76 \mathrm{eV}$ for coverages of $0.125-0.5 \mathrm{ML}$ and thereafter decreases to $3.40 \mathrm{eV}$ at $1 \mathrm{ML}$, as shown in Fig. 2(a). Typically, on-surface adsorption of electronegative adsorbates on a metal surface leads to a decreasing binding energy with increasing coverage, which is due to a repulsive interaction between these electronegative atoms at close distances (i.e., high coverages). Our binding energy trend deviates from this, implying that the internitrogen interaction on $\mathrm{Cu}$ (100) is attractive at $0.5 \mathrm{ML}$ coverage. This is consistent with the observed island formation with a local $\mathrm{N}$ coverage of 0.5 $\mathrm{ML}$, with a $\mathrm{Cu}(100)-c(2 \times 2)-\mathrm{N}$ local structure. As the coverage of nitrogen is increased, the size of the islands increases, forming a uniform $\mathrm{Cu}(100)-c(2 \times 2)-\mathrm{N}$ structure at saturation. $^{12}$

In the relaxed structures at coverages of 0.75 and $1 \mathrm{ML}$ on $\mathrm{Cu}$ (100), the $\mathrm{N}$ atoms are not all positioned above the surface $\mathrm{Cu}$ layer. At $0.75 \mathrm{ML}$ coverage, the relaxed structure consists of two $\mathrm{N}$ atoms situated above the $\mathrm{Cu}$ substrate and one situated below the top layer, while at a coverage of 1 $\mathrm{ML}$, all $\mathrm{N}$ atoms are positioned $0.47 \AA$ below the $\mathrm{Cu}$ surface layer. These structures have a low binding energy, compared to the low-coverage adsorption phases, with binding energies of only $3.74 \mathrm{eV}$ and $3.40 \mathrm{eV}$, for the $0.75-\mathrm{ML}$ and 1-ML structures, respectively. A second 1-ML N/Cu (100) structure was examined, with the $\mathrm{N}$ atoms initially positioned $0.65 \AA$ above the surface, compared to $0.21 \AA$ for the initial 0.75-ML and 1-ML structures. The relaxed (metastable) structure has all $\mathrm{N}$ atoms $0.49 \AA$ above the surface, with a binding energy of $3.01 \mathrm{eV}$, which is lower than the binding energy for $1 \mathrm{ML}$ coverage in the subsurface sites. The preference for the subsurface site, compared to the on-surface site, could be due to the additional coordination of the $\mathrm{N}$ atom to the $\mathrm{Cu}$ atoms in the second layer and a consequent more effective screening of the partially charged and closely positioned $\mathrm{N}$ atoms.

To correlate the binding energy trend with surface geometry, we examine the structural properties of $\mathrm{N}$ adsorbed on $\mathrm{Cu}$. Table I lists average bond lengths between adsorbed $\mathrm{N}$ and $\mathrm{Cu}$ atoms and the interlayer spacings between the outer 
TABLE I. Calculated geometric structural parameters (in $\AA$ ) for different surface structures at nitrogen coverages $\Theta$ and $\mathrm{N}$ binding energy $E_{\mathrm{b}}^{\mathrm{N} / \mathrm{Cu}}$ (in eV) with respect to the free nitrogen atom. $d_{\mathrm{Cu}-\mathrm{N}}$ indicates the average bond length between nitrogen and the nearest copper atom. $d_{\mathrm{N} 1}$ is the planar averaged vertical height of $\mathrm{N}$ above the topmost $\mathrm{Cu}$ layer. $d_{\mathrm{N}^{\prime} 0}$ is defined to be the maximum negative displacement between the $\mathrm{N}$ atom and the topmost $\mathrm{Cu}$ layer, while $d_{\mathrm{N} 0}$ is defined to be the largest positive vertical displacement between a $\mathrm{N}$ atom and the topmost $\mathrm{Cu}$ layer. $d_{12}$ and $d_{23}$ are the first and second unreconstructed $\mathrm{Cu}$ interlayer distances, where the center of mass of the layers is used. The computed bulk $\mathrm{Cu}(100)$ interlayer spacing is $1.82 \AA$, and $d_{\mathrm{Cu}-\mathrm{N}}$ in bulk $\mathrm{Cu}_{3} \mathrm{~N}$ is $1.92 \AA$. Nitrogen coverage $\Theta$ (in $\mathrm{ML}$ ) for each structure is shown in brackets.

\begin{tabular}{|c|c|c|c|c|c|c|}
\hline & $\begin{array}{c}\mathrm{Cu}(100)-p(2 \times 4)-\mathrm{N} \\
(0.125 \mathrm{ML})\end{array}$ & $\begin{array}{c}\mathrm{Cu}(100)-p(2 \times 2)-\mathrm{N} \\
(0.25 \mathrm{ML})\end{array}$ & $\begin{array}{c}\mathrm{Cu}(100)-c(2 \times 2)-\mathrm{N} \\
(0.50 \mathrm{ML})\end{array}$ & $\begin{array}{c}\mathrm{Cu}(100)-p(2 \times 2)-3 \mathrm{~N} \\
(0.75 \mathrm{ML})\end{array}$ & $\begin{array}{c}\mathrm{Cu}(100)-p(1 \times 1)-\mathrm{N}_{\mathrm{S}} \\
(1.00 \mathrm{ML})\end{array}$ & $\begin{array}{c}\mathrm{Cu}(100)-p(1 \times 1)-\mathrm{N}_{\mathrm{SS}} \\
(1.00 \mathrm{ML})\end{array}$ \\
\hline$d_{\mathrm{Cu}-\mathrm{N}}$ & 1.92 & 1.92 & 1.83 & 1.90 & 1.89 & 1.90 \\
\hline$d_{\mathrm{N} 1}$ & 0.44 & 0.48 & 0.21 & 0.07 & 0.49 & -0.47 \\
\hline$d_{\mathrm{N}^{\prime} 0}$ & - & - & - & -0.56 & - & -0.47 \\
\hline$d_{\mathrm{N} 0}$ & - & - & - & 0.40 & - & - \\
\hline$d_{12}$ & 1.81 & 1.85 & 1.97 & 2.25 & 2.25 & 2.46 \\
\hline$d_{23}$ & 1.83 & 1.83 & 1.83 & 1.82 & 1.82 & 1.81 \\
\hline$E_{\mathrm{b}}^{\mathrm{N} / \mathrm{Cu}}$ & 4.50 & 4.52 & 4.76 & 3.74 & 3.02 & 3.40 \\
\hline
\end{tabular}

$\mathrm{Cu}$ layers. A shorter $\mathrm{Cu}-\mathrm{N}$ bond length is indicative of a stronger $\mathrm{Cu}-\mathrm{N}$ bond and thus may indicate a more stable structure. The bond length $d_{\mathrm{Cu}-\mathrm{N}}$ for the $\mathrm{Cu}$ (100)-c (2 $\times 2)$-N structure is $0.09 \AA$ smaller than $d_{\mathrm{Cu}-\mathrm{N}}$ for $\mathrm{Cu}(100)-p(2 \times 2)-\mathrm{N}$, which correlates well with the binding energy calculations, as the $\mathrm{Cu}(100)-c(2 \times 2)-\mathrm{N}$ structure is $0.24 \mathrm{eV}$ more favorable than the $\mathrm{Cu}(100)-p(2 \times 2)-\mathrm{N}$ structure. Also, in Table I, it is seen that the interlayer distance $d_{12}$ increases from $1.81 \AA$ at $0.125 \mathrm{ML}$ to $2.25 \AA$ at a full ML on-surface coverage, whereas $d_{23}$ remains almost constant $(\sim 1.82 \AA)$ for all considered coverages of $\mathrm{N}$. The large variation in $d_{12}$ reflects the stronger $\mathrm{N}-\mathrm{Cu}$ bonds formed on the $\mathrm{Cu}(100)$ surface which weaken the $\mathrm{Cu}-\mathrm{Cu}$ bonds of the first layer $\mathrm{Cu}$ atoms to the underlying $\mathrm{Cu}$ atoms in the substrate and hence explains the almost constant value of $d_{23}$. Overall, our calculated structural parameters compare well with another DFT study of the $\mathrm{Cu}(100)-c(2 \times 2)-\mathrm{N}$ phase, ${ }^{17}$ which determined the $\mathrm{Cu}-\mathrm{N}$ bond length to be $1.83 \AA$ and $d_{\mathrm{N} 1}=0.20 \AA$, and an experimental study, ${ }^{60}$ which reported $d_{\mathrm{Cu}-\mathrm{N}}=1.85 \AA$.

\section{Nitrogen adsorption on $\mathrm{Cu}(110)$}

The $\mathrm{Cu}$ (110) surface reconstruction adsorption phases studied include (i) a surface nitridelike structure $\mathrm{Cu}(110)-p(2 \times 3)-4 \mathrm{~N}\left(\Theta_{\mathrm{N}}=0.66 \mathrm{ML}\right)[$ Fig. $1(\mathrm{e})]$, (ii) nitrogen adsorption in the LB site on the [001] missing-row $\mathrm{Cu}$ (110) surface $\mathrm{Cu}(110)-p(2 \times 3)-2 \mathrm{~N}\left(\Theta_{\mathrm{N}}=0.33 \mathrm{ML}\right)$ [Fig. $1(\mathrm{c})]$, and (iii) nitrogen chemisorption on the [110] missingrow $\mathrm{Cu}(110)$ surface in the $\mathrm{LB}$ site, $\mathrm{Cu}(110)-p(2 \times 3)-\mathrm{N}$ $\left(\Theta_{\mathrm{N}}=0.17 \mathrm{ML}\right)[$ Fig. 1(d)]. We also investigate nitrogen adsorption at the $\mathrm{SB}, 4 \mathrm{FH}$, and $3 \mathrm{FH}$ (pseudo-threefold-hollow) sites at a low coverage of $\frac{1}{6} \mathrm{ML}$. In addition, chemisorption on an unreconstructed $\mathrm{Cu}$ (110) surface is studied in the SB site at $0.25 \mathrm{ML}$ coverage, in the LB site from 0.125 to 0.5 $\mathrm{ML}$, and in the 4FH hollow site from 0.125 to $1 \mathrm{ML}$.

From Fig. 2(b), it can be seen that the surface nitride structure $\mathrm{Cu}(110)-p(2 \times 3)-4 \mathrm{~N}$ has the most favorable binding energy for all considered $\mathrm{Cu}$ (110) adsorption phases, having an average binding energy of $4.71 \mathrm{eV}$. After this, the
$\mathrm{Cu}(110)-p(2 \times 3)-2 \mathrm{~N}$ structure is the next most favorable, with a binding energy of $4.33 \mathrm{eV}$, while the $\mathrm{Cu}$ (110)-p(2 $\times 3)$-N structure on the [110] missing-row surface has a binding energy of $3.79 \mathrm{eV}$. The latter structure is not the most energetically favored structure on the [110] missing-row surface. The most favorable site for $\mathrm{N}$ on the [110] missing-row surface is where $\mathrm{N}$ is in the $4 \mathrm{FH}$ site-i.e., fourfold coordinated to the surface $\mathrm{Cu}$ atoms and onefold coordinated to the $\mathrm{Cu}$ directly below in the second substrate layer $\left(\Theta_{\mathrm{N}}\right.$ $=0.17 \mathrm{ML}$ ), which has a binding energy of $4.00 \mathrm{eV}$ [not shown in Fig. 2(b)].

For chemisorption on the unreconstructed $\mathrm{Cu}(110)$ surface, the most favorable adsorption site at $0.25 \mathrm{ML}$ coverage is the $4 \mathrm{FH}$ site, with a binding energy of $4.13 \mathrm{eV}$, compared to $3.97 \mathrm{eV}$ at the $\mathrm{LB}$ site and $3.03 \mathrm{eV}$ at the $\mathrm{SB}$ site (not shown). For $\mathrm{N}$ adsorption at the $4 \mathrm{FH}$ site, the binding energy decreases with increasing coverage, while for that at the LB site, the binding energy plateaus with increasing coverage. For coverages below $0.25 \mathrm{ML}$, the $4 \mathrm{FH}$ site is favored over the LB site. However, as the coverage increases above $\sim 0.3 \mathrm{ML}$, the LB site becomes preferred over the $4 \mathrm{FH}$ site.

From Table II it can be seen that, unlike for N/Cu (100), the trend in binding energy for $\mathrm{N} / \mathrm{Cu}$ (110) surface reconstructions is not reflected in the $\mathrm{Cu}-\mathrm{N}$ bond lengths. In particular, the $\mathrm{Cu}-\mathrm{N}$ bond length for the most favorable $\mathrm{Cu}(110)-p(2 \times 3)-4 \mathrm{~N}$ structure is actually about $0.5 \%$ longer than that of the less favorable $\mathrm{Cu}(110)$ surface reconstructions that we have considered. However, the observed $d_{\mathrm{Cu}-\mathrm{N}}$ for $\mathrm{Cu}(110)-p(2 \times 3)-4 \mathrm{~N}$ is only $0.02 \AA$ smaller than the $\mathrm{Cu}-\mathrm{N}$ bond length of bulk copper nitride and the atomic structure of the surface nitride closely resembles the structure of bulk copper nitride. This suggests that the $\mathrm{Cu}$ (110)-p (2 $\times 3)-4 \mathrm{~N}$ structure may be a precursor to the formation of the bulk copper nitride phase. In addition, due to the favoring of these more complex surface nitridelike structures, the interlayer distances $d_{12}$ and $d_{23}$ do not correlate with increasing $\mathrm{N}$ coverage. Overall, $d_{12}$ remains fairly constant, with the exception of $\mathrm{Cu}(110)-p(2 \times 3)-4 \mathrm{~N}$ and $\mathrm{Cu}(110)-p(2 \times 4)-\mathrm{N}$ having a contraction of $3.8 \%$ and $6.2 \%$, respectively. On the other hand, unlike for $\mathrm{N} / \mathrm{Cu}(100), d_{23}$ does not remain a 
TABLE II. Calculated geometric structural parameters (in $\AA$ ) for different surface structures at nitrogen coverages $\Theta$ and the $\mathrm{N}$ binding energy $E_{\mathrm{b}}^{\mathrm{N} / \mathrm{Cu}}$ (in eV) with respect to the free nitrogen atom. $d_{\mathrm{Cu}-\mathrm{N}}$ indicates the average bond length between nitrogen and the nearest copper atom. $d_{\mathrm{N} 1}$ is the planar averaged vertical height of $\mathrm{N}$ above the topmost $\mathrm{Cu}$ layer. For the surface reconstructions and surface nitrides, $d_{\mathrm{N}^{\prime} 1}$ is defined to be the distance between the middle of the surface nitride layer and the first layer of unreconstructed $\mathrm{Cu}$ atoms. $d_{\mathrm{N} 0}$ is defined to be the largest positive vertical displacement between a $\mathrm{N}$ atom and the topmost $\mathrm{Cu}$ layer. $d_{12}$ and $d_{23}$ are the first and second unreconstructed $\mathrm{Cu}$ interlayer distances, where the center of mass of the layer is used. The computed bulk $\mathrm{Cu}$ interlayer spacing is $1.30 \AA$ for $\mathrm{Cu}$ (110) and $2.10 \AA$ for $\mathrm{Cu}(111)$, and $d_{\mathrm{Cu}-\mathrm{N}}$ in bulk $\mathrm{Cu}_{3} \mathrm{~N}$ is $1.92 \AA$. Nitrogen coverage $\Theta$ (in ML) for each structure is shown in brackets.

\begin{tabular}{|c|c|c|c|c|c|}
\hline & $\begin{array}{c}\mathrm{Cu}(110)-p(2 \times 3)-\mathrm{N} \\
(0.17 \mathrm{ML})\end{array}$ & $\begin{array}{c}\mathrm{Cu}(110)-p(2 \times 3)-2 \mathrm{~N} \\
(0.33 \mathrm{ML})\end{array}$ & $\begin{array}{c}\mathrm{Cu}(110)-p(2 \times 3)-4 \mathrm{~N} \\
(0.66 \mathrm{ML})\end{array}$ & $\begin{array}{c}\mathrm{Cu}(110)-p(2 \times 4)-\mathrm{N} \\
(0.125 \mathrm{ML})\end{array}$ & $\begin{array}{l}\text { N/Cu (111)-“16" } \\
(0.44 \mathrm{ML})\end{array}$ \\
\hline$d_{\mathrm{Cu}-\mathrm{N}}$ & 1.89 & 1.88 & 1.90 & 2.01 & 1.85 \\
\hline$d_{\mathrm{N} 1}$ & 0.25 & 0.11 & 0.13 & 0.45 & 0.14 \\
\hline$d_{\mathrm{N}^{\prime} 1}$ & 1.23 & 1.30 & 1.99 & - & 2.36 \\
\hline$d_{\mathrm{N} 0}$ & - & - & 0.66 & - & 0.53 \\
\hline$d_{12}$ & 1.31 & 1.29 & 1.25 & 1.22 & 2.10 \\
\hline$d_{23}$ & 1.21 & 1.28 & 1.28 & 1.33 & 2.10 \\
\hline$E_{\mathrm{b}}^{\mathrm{N} / \mathrm{Cu}}$ & 3.78 & 4.33 & 4.71 & 4.24 & 4.35 \\
\hline
\end{tabular}

constant with varying $\mathrm{N}$ coverage. A small contraction of $1.5 \%$ is observed for both $\mathrm{Cu}(110)-p(2 \times 3)-2 \mathrm{~N}$ and $\mathrm{Cu}(110)-p(2 \times 3)-4 \mathrm{~N}$, while a larger contraction of $7.7 \%$ is seen for $\mathrm{Cu}(110)-p(2 \times 3)-\mathrm{N}$ and an expansion of $2.3 \%$ for $\mathrm{Cu}(110)-p(2 \times 4)-\mathrm{N}$.

\section{Nitrogen adsorption on $\mathrm{Cu}$ (111)}

Our previous study ${ }^{39}$ examined $\mathrm{N}$ adsorption on $\mathrm{Cu}$ (111) in the fcc and hcp threefold hollow sites for coverages ranging from 0.125 to $1 \mathrm{ML}$. The experimentally observed surface nitride structure was modeled through both a " 4 " and a "16" reconstructed structure [Figs. $1(\mathrm{~g})-1(1)$ ]. The most favorable geometry was found to be the "16" reconstruction, shown in Figs. 1(g) and 1(h), which has an average binding energy per $\mathrm{N}$ atom of $4.35 \mathrm{eV}$ at $\frac{7}{16} \mathrm{ML}$ coverage [see Fig. 2(c)]. For further details we refer to Ref. 39.

\section{Comparison of nitrogen adsorption on $\mathrm{Cu}$ (100), (110), and (111)}

This study has found that the most energetically favored nitrogen adsorption phase on $\mathrm{Cu}(100)$ is the $\mathrm{Cu}$ (100)-c(2 $\times 2)$-N structure, while on $\mathrm{Cu}(110)$, the experimentally observed surface nitride $\mathrm{Cu}(110)-p(2 \times 3)-4 \mathrm{~N}$ is the most preferred. For $\mathrm{Cu}$ (111), the surface nitride "16" structure is found to have the most favorable binding energy, compared to the other surface nitride and chemisorption structures considered on the (111) surface of $\mathrm{Cu}$. Evidently, from Fig. 2, the $\mathrm{Cu}(100)-c(2 \times 2)-\mathrm{N}$ structure has the most favorable binding energy of all considered $\mathrm{N} / \mathrm{Cu}$ low-index surface structures. We attribute the relative stability of these surface structures in terms of an interplay of two contributions to the nitrogen binding energy: (i) the average strain of the structures considered relative to the $\mathrm{N}-\mathrm{Cu}-\mathrm{N}$ bonds in bulk $\mathrm{Cu}_{3} \mathrm{~N}$ and (ii) the energy cost of forming these N/Cu reconstruction structures: The average strain is calculated by taking the difference (in percent) between the horizontal distance (parallel to the surface) spanned by $\mathrm{N}-\mathrm{Cu}-\mathrm{N}$ bonds in the $\mathrm{Cu}(100)-c(2 \times 2)-\mathrm{N}$ and surface nitride structures and the distance spanned by N-Cu-N bonds of bulk $\mathrm{Cu}_{3} \mathrm{~N}$. This results in a strain of $-5.30 \%,-1.65 \%$, and $-5.20 \%$ for the $\mathrm{Cu}(100)-c(2 \times 2)-\mathrm{N}, \quad \mathrm{Cu}(110)-p(2 \times 3)-4 \mathrm{~N}, \quad$ and " $16 "$ structures, respectively. The $\mathrm{Cu}(110)-p(2 \times 3)-4 \mathrm{~N}$ structure has the lowest strain, and if one only considers the strain, one would expect this to be the most favorable structure. However, the energy cost of reconstructing the $\mathrm{Cu}(110)$ and $\mathrm{Cu}$ (111) surfaces into the pseudo-Cu-(100)-like structure for $\mathrm{N}$ adsorption in a surface nitride phase also contributes significantly to the overall binding energy of these structures. For $\mathrm{Cu}(100)$, there is also an energy cost in the relaxation of $\mathrm{Cu}$ atoms into the same atomic positions as that in the $\mathrm{Cu}(100)-c(2 \times 2)-\mathrm{N}$ phase. We calculate the energy cost per nitrogen atom, $E_{\text {cost }}$, as follows:

$$
E_{\mathrm{cost}}=\frac{1}{N_{\mathrm{N}}}\left[E_{\mathrm{Cu}}^{\mathrm{relax}}-\left(E_{\mathrm{Cu}}^{\mathrm{ideal}}-\Delta N_{\mathrm{Cu}} E_{\mathrm{Cu}}\right)\right],
$$

where $N_{\mathrm{N}}$ is the number of nitrogen atoms in the corresponding $\mathrm{N} / \mathrm{Cu}$ system, $E_{\mathrm{Cu}}^{\mathrm{relax}}$ is the total energy of the reconstructed copper slab (without $\mathrm{N}$ ) having the same fixed atomic positions as the $\mathrm{N} / \mathrm{Cu}$ system, $E_{\mathrm{Cu}}^{\text {ideal }}$ is the energy of an ideal, relaxed copper slab, without any reconstruction, $\Delta N_{\mathrm{Cu}}$ is the difference in the number of $\mathrm{Cu}$ atoms between the reconstructed $\mathrm{Cu}$ surface and the ideal $\mathrm{Cu}$ surface (i.e., considering a symmetric slab with two identical surfaces exposed), and $E_{\mathrm{Cu}}$ is the energy of a single $\mathrm{Cu}$ atom in bulk $\mathrm{Cu}$.

The calculated value of $E_{\text {cost }}$ is $0.14,0.57$, and $0.78 \mathrm{eV}$ for the $\mathrm{Cu}(100)-c(2 \times 2)-\mathrm{N}, \mathrm{Cu}(110)-p(2 \times 3)-4 \mathrm{~N}$, and " 16 " structures, respectively. The energy cost in forming the $\mathrm{Cu}(100)-c(2 \times 2)-\mathrm{N}$ structure is much lower than that of the surface nitride structures on $\mathrm{Cu}(110)$ and $\mathrm{Cu}$ (111) because the $\mathrm{Cu}(100)-c(2 \times 2)-\mathrm{N}$ structure is formed by simple chemisorption and requires minimal relaxation of surface $\mathrm{Cu}$ atoms, while for the $\mathrm{Cu}$ (110) and $\mathrm{Cu}$ (111) surface nitride structures, $\mathrm{Cu}$ atoms are strongly displaced from their original position on the clean $\mathrm{Cu}$ surface [i.e., added to and removed from the ideal $\mathrm{Cu}$ substrate, respectively, for $\mathrm{Cu}$ (110) and $\mathrm{Cu}(111)]$. Thus, despite having the highest strain com- 
pared to the surface nitride structures, it costs the $\mathrm{Cu}(100)-c(2 \times 2)-\mathrm{N}$ phase the least energy to form this surface atomic configuration, and enough energy is gained from $\mathrm{N}$ adsorption to become the most energetically favored $\mathrm{N} / \mathrm{Cu}$ surface structure. The "16" structure is the least favorable structure, as it has the largest $E_{\text {cost }}$ compared to the other structures, possibly due to the stability of the clean $\mathrm{Cu}$ (111) surface.

Equation (4) is also used to determine the distortion energy of the $\mathrm{Cu}(100)$ surface, which is of interest because of the subsurface positions of $\mathrm{N}$ atoms in the relaxed adsorption phases at the high coverages of 0.75 and $1 \mathrm{ML}$. $E_{\text {cost }}$ is calculated to be 0.40 and $0.45 \mathrm{eV}$ for the $0.75-\mathrm{ML}$ and $1-\mathrm{ML}$ structures, respectively. This in part is responsible for the notably smaller binding energies as compared to the lowercoverage structures. The other factor contributing to the weak binding of $\mathrm{N}$ in the $0.75-\mathrm{ML}$ and $1.0-\mathrm{ML}$ structures is the repulsive interaction between the closely situated and partially negatively charged $\mathrm{N}$ atoms.

\section{Electronic properties}

The electronic structure of $\mathrm{N}$ adsorbates on $\mathrm{Cu}$ is now presented. The calculated change in work function $(\Delta \Phi)$, with respect to the clean $\mathrm{Cu}$ surface, and $\mathrm{N}$-induced surface dipole moment $(\mu)$ as a function of coverage for the lowindex surfaces are displayed in Fig. 3. The work function is defined to be the difference between the electrostatic potential in the vacuum and the Fermi energy of the slab. The surface dipole moment $\mu$ (in Debye) is evaluated by the Helmholtz equation

$$
\mu=\frac{A \Delta \Phi}{12 \pi \Theta},
$$

where $A$ is the area in $\AA^{2}$ per $(1 \times 1)$ surface unit cell, $\Delta \Phi$ is the work-function change in $\mathrm{eV}$, and $\Theta$ is the coverage in monolayers.

The surface dipole moment is found to decrease with increasing coverage for the $\mathrm{Cu}(100)$ and $\mathrm{Cu}(110)$ structures. This behavior can be understood by considering the electron transfer process between adsorbate and substrate atoms: There is a substantial electronegativity difference between $\mathrm{N}$ and $\mathrm{Cu}(3.04-1.90=1.14),{ }^{59}$ so electrons are transferred (or part thereof) from the $\mathrm{Cu}$ to $\mathrm{N}$ atoms. However, with increasing coverage, there will be a repulsive interaction between the partially negatively charged $\mathrm{N}$ atoms. To counter this repulsion, there will be a partial charge transfer of electron density back to the substrate, thus decreasing the surface dipole moment. The surface dipole moment is negative for the 1-ML Cu (100) subsurface structure, due to the position of the electronegative $\mathrm{N}$ atoms below the $\mathrm{Cu}$ surface. This results in a net positive charge at the surface and hence an outward-pointing, negative dipole moment.

For electronegative adsorbates, $\Delta \Phi$ typically increases with coverage, as more effective negative charges are added to the surface. This is observed in the $\mathrm{Cu}(100)$ chemisorption phases, where $\Delta \Phi$ increases from $0.29 \mathrm{eV}$ at $0.125 \mathrm{ML}$ to $1.96 \mathrm{eV}$ for $1 \mathrm{ML}$ coverage of $\mathrm{N}$, positioned above the surface. The sharp drop in $\Delta \Phi$ for the 1-ML Cu (100) sub-
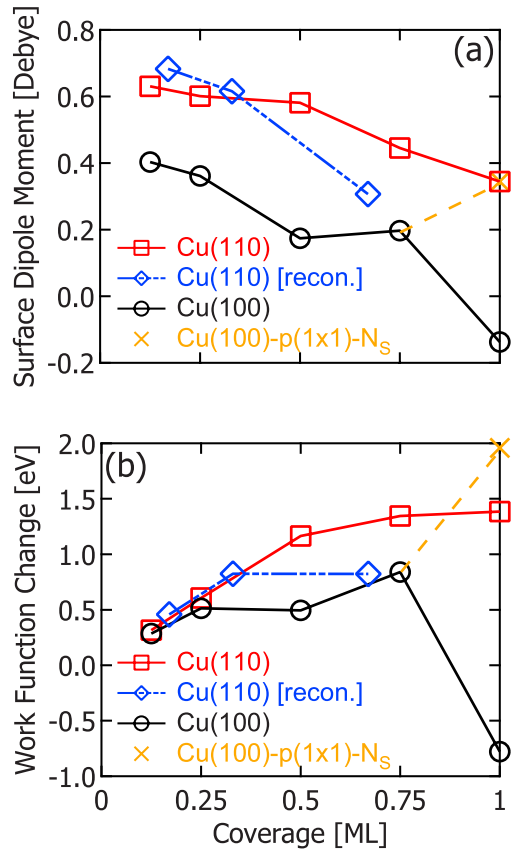

FIG. 3. (Color online) Calculated (a) surface dipole moment $(\mu)$ and (b) work-function change $(\Delta \Phi)$ relative to the clean $\mathrm{Cu}$ surface as a function of coverage for $\mathrm{N}$ adsorption at the $4 \mathrm{FH}$ site on the $\mathrm{Cu}$ (100) (shown as open-circle data points) and $\mathrm{Cu}$ (110) (shown as open-square data points) surfaces. The diamond-shaped data points labeled as " $\mathrm{Cu}$ (110) [recon.]" represent the following structures: $\mathrm{Cu}(110)-p(2 \times 3)-\mathrm{N}$ at $0.17 \mathrm{ML}, \mathrm{Cu}(110)-p(2 \times 3)-2 \mathrm{~N}$ at 0.33 $\mathrm{ML}$, and $\mathrm{Cu}(110)-p(2 \times 3)-4 \mathrm{~N}$ at $0.66 \mathrm{ML}$. $\mathrm{Cu}(100)-p(1$ $\times 1)-\mathrm{N}_{\mathrm{S}}$ is the full monolayer $\mathrm{N} / \mathrm{Cu}(100)$ structure with nitrogen atoms adsorbed on the surface in the $4 \mathrm{FH}$ site.

surface structure is due to the position of $\mathrm{N}$ below the surface. From Eq. (5), it is clear that a negative surface dipole moment results in a negative-work function change. The 0.5ML-coverage structure $\mathrm{Cu}(100)-c(2 \times 2)-\mathrm{N}$ has a slightly lower work-function change compared to the 0.25 -ML structure on $\mathrm{Cu}(100)$. This may be attributed to screening effects: the $\mathrm{N}$ atom in the $\mathrm{Cu}(100)-c(2 \times 2)-\mathrm{N}$ structure is positioned $0.21 \AA$ above the surface $\mathrm{Cu}$ layer, while $\mathrm{N}$ in the $\mathrm{Cu}(100)-p(2 \times 2)-\mathrm{N}$ structure is $0.48 \AA$ above the surface $\mathrm{Cu}$ layer. Hence, the contributions to $\Delta \Phi$ from the $\mathrm{N}$ atoms may be reduced due a more efficient screening from the $\mathrm{Cu}$ atoms in the $\mathrm{Cu}(100)-c(2 \times 2)-\mathrm{N}$ structure.

Utilizing the simple relation that the surface dipole $\mu$ is proportional to the product of the averaged vertical distance of $\mathrm{N}$ (i.e., $d_{\mathrm{N} 1}$ ) from the substrate and the effective electronic charge on $\mathrm{N}, Q_{\mathrm{N}}$, we can estimate the surface dipole moment. ${ }^{47} Q_{\mathrm{N}}$ is estimated from the Mulliken population partition method. This form of charge population analysis, although not an absolute measure of the exact charge distribution, does provide a consistent measure of relative electronic charge (re)distribution. The average height of the $\mathrm{N}$ atom with respect to the top $\mathrm{Cu}$ layer, $d_{\mathrm{N} 1}$, for the $\mathrm{Cu}(100)-c(2 \times 2)-\mathrm{N}$ and $\mathrm{Cu}(100)-p(2 \times 2)-\mathrm{N}$ structures is 0.21 and $0.48 \AA$, respectively. Their corresponding $Q_{\mathrm{N}}$ values are $0.74 e$ and $0.65 e$. Thus, for $\mathrm{Cu}(100)-c(2 \times 2)-\mathrm{N}$, the product is $d_{\mathrm{N} 1} Q_{\mathrm{N}}=0.16 e \AA$ and that for $\mathrm{Cu}(100)-p(2$ $\times 2)$ - $\mathrm{N}$ is $0.31 e \AA$. From this simple analysis, one can then 

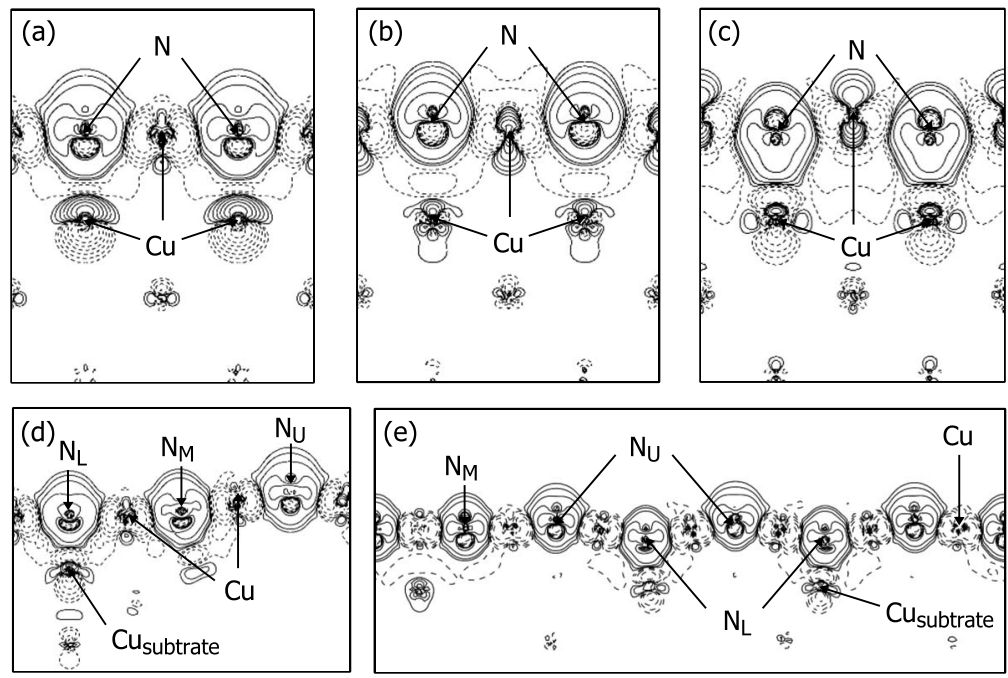

FIG. 4. Difference charge densities of (a) $\mathrm{Cu}(100)-c(2 \times 2)-\mathrm{N}$, (b) $\mathrm{Cu}(100)-p(1 \times 1)-\mathrm{N}_{\mathrm{S}}$, (c) $\mathrm{Cu}(100)-p(1 \times 1)-\mathrm{N}_{\mathrm{SS}}, \quad$ (d) $\mathrm{Cu}(110)-p(2$ $\times 3)-4 \mathrm{~N}$, and (e) N/Cu (111):"16" structure. All plots are viewed along the $\mathrm{N}-\mathrm{Cu}-\mathrm{N}$ bond. The dashed lines represent regions of charge depletion, and the solid lines depict regions of charge accumulation. The lowest positive contour line corresponds to 0.001 electron bohr $^{-3}$, while the highest negative contour line corresponds to a value of -0.001 electron bohr $^{-3}$. In between, the electron density changes successively by a factor of $10^{1 / 3}$ electron bohr $^{-3}$. easily see why $\mathrm{Cu}(100)-c(2 \times 2)-\mathrm{N}$ has a lower workfunction change compared to $\mathrm{Cu}(100)-p(2 \times 2)-\mathrm{N}$.

The trend in work-function change for $\mathrm{N}$ chemisorption in the $4 \mathrm{FH}$ site of the unreconstructed $\mathrm{Cu}$ (110) surface increases with coverage, similar to the chemisorption phase on $\mathrm{Cu}$ (100). For the reconstruction phases, the $\mathrm{Cu}(110)-p(2$ $\times 3)-2 \mathrm{~N}$ and $\mathrm{Cu}(110)-p(2 \times 3)-4 \mathrm{~N}$ structures, corresponding to coverages of $0.33 \mathrm{ML}$ and $0.66 \mathrm{ML}$, respectively, have almost identical work functions.

The $\Delta \Phi$ trend for the reconstructed N/Cu (110) structures can be understood again by calculating the estimated surface dipole moment using the effective electronic charges on $\mathrm{N}$ in these two structures and the average height of the $\mathrm{N}$ atom with respect to the top $\mathrm{Cu}$ layer, $d_{\mathrm{N} 1}$ : for the $\mathrm{Cu}(110)-p(2$ $\times 3)-2 \mathrm{~N}$ structure, $d_{\mathrm{N} 1}=0.11 \AA$, and for $\mathrm{Cu}(110)-p(2$ $\times 3)-4 \mathrm{~N}, d_{\mathrm{N} 1}=0.13 \AA$, i.e., they are comparable. However, the $\mathrm{Cu}(110)-p(2 \times 3)-4 \mathrm{~N}$ structure experiences greater screening effects due to the higher coordination of $\mathrm{N}$ atoms in this structure: $\mathrm{N}$ is bonded to four surface $\mathrm{Cu}$ atoms in the $\mathrm{Cu}(110)-p(2 \times 3)-4 \mathrm{~N}$ structure, while $\mathrm{N}$ is bonded to two surface $\mathrm{Cu}$ atoms in the $\mathrm{Cu}(110)-p(2 \times 2)-2 \mathrm{~N}$ structure. The resulting values of $Q_{\mathrm{N}}$ are $0.73 e$ and $0.67 e$, respectively. This results in $\mathrm{Cu}(110)-p(2 \times 3)-2 \mathrm{~N}$ having a value of $d_{\mathrm{N} 1} Q_{\mathrm{N}}=0.07 e \AA$ and $\mathrm{Cu}(110)-p(2 \times 3)-4 \mathrm{~N}$ a value of $0.09 e \AA$, and this correlates well with the actual DFTcalculated surface dipole moments.

The difference electron density distributions for selected $\mathrm{N} / \mathrm{Cu}(100)$ and surface nitride phases, in planes perpendicular to the surface along the $\mathrm{N}-\mathrm{Cu}$ bond, are presented in Fig. 4. These quantities are calculated as

$$
n^{\Delta}(\mathbf{r})=n^{\mathrm{N} / \mathrm{Cu}}(\mathbf{r})-n^{\mathrm{Cu}}(\mathbf{r})-n^{\mathrm{N}}(\mathbf{r})
$$

Here $n^{\mathrm{N} / \mathrm{Cu}}$ is the total electron density of the substrate/ adsorbate system, from which the electron density of both the clean surface, $n^{\mathrm{Cu}}$, and that of the corresponding isolated nitrogen adlayer, $n^{\mathrm{N}}$, are subtracted. The positions of the pure $\mathrm{Cu}$ surface and nitrogen atoms are taken to be the ones of the relaxed adsorbate system and are kept fixed.

For the selected N/Cu surface structures shown in Fig. 4, we note some similarities: The nitrogen atoms appear to be almost coplanar with the adjacent $\mathrm{Cu}$ atoms. The electron densities of the nearest-neighbor $\mathrm{Cu}$ atoms are depleted (depicted as dotted lines in Fig. 4), while the electron densities of $\mathrm{N}$ atoms are enhanced (depicted as solid lines in Fig. 4). This can be attributed to the large electronegativity of N. The accumulation of electron density on the vacuum side of the surface for $\mathrm{N}$ results in an inward pointing surface dipole moment and a positive $\Delta \Phi$. The impact of the $\mathrm{N}$ atoms on its neighboring $\mathrm{Cu}$ atoms can also be seen to extend to the second $\mathrm{Cu}$ substrate layer. In particular, for the surface nitride reconstructions, there are $\mathrm{N}$ atoms which affect $\mathrm{Cu}$ atoms in the reconstructed layer as well as in the first layer of the unreconstructed slab.

To illustrate the difference in surface dipole moment observed for subsurface N/Cu (100) adsorption phase (at $1 \mathrm{ML}$ ) $\mathrm{Cu}(100)-p(1 \times 1)-\mathrm{N}_{\mathrm{SS}}$ and the corresponding on-surface adsorption phase $\mathrm{Cu}(100)-p(1 \times 1)-\mathrm{N}_{\mathrm{S}}$, their respective difference electron density distributions are shown in Figs. 4(a) and $4(\mathrm{~b})$. The electron density for $\mathrm{Cu}(100)-p(1 \times 1)-\mathrm{N}_{\mathrm{S}}$ resembles that of the $\mathrm{Cu}(100)-c(2 \times 2)-\mathrm{N}$ structure. However, for $\mathrm{Cu}(100)-p(1 \times 1)-\mathrm{N}_{\mathrm{SS}}$, it is clear that the electron density enhancement of the $\mathrm{N}$ atoms is concentrated below the $\mathrm{Cu}$ surface, thus leading to the outward-pointing surface dipole moment and negative $\Delta \Phi$. Furthermore, from the depleted electron density of the neighboring surface and second-layer $\mathrm{Cu}$ atoms, it is clear that $\mathrm{N}$ in this structure not only interacts and bonds to $\mathrm{Cu}$ atoms on the surface, but also with $\mathrm{Cu}$ atoms below the surface.

The projected densities-of-states (PDOS) are presented in Figs. 5 and 6. In Fig. 5, for the $0.5 \mathrm{ML} \mathrm{Cu}$ (100)-c(2 $\times 2$ )-N structure, single particle wave functions are also plotted at the $\Gamma$ point for various different energy eigenvalues. In all cases, we observe a renormalization of the $\mathrm{N} 2 p$ energy levels to lower energies and a hybridization between $\mathrm{N} 2 p$ and $\mathrm{Cu} 3 d$ states in the region from -8 to $-4 \mathrm{eV}$. The PDOS for the $\mathrm{Cu}(100)-c(2 \times 2)-\mathrm{N}$ structure in Fig. 5 bears some resemblance to the PDOS corresponding to bulk $\mathrm{Cu}_{3} \mathrm{~N}$ [see Fig. 9(a) in Ref. 39]; however, there is a noticeable peak at around $-4 \mathrm{eV}$, which is absent from the PDOS corresponding to the bulk structure. Plotting the spatial distribution of the single-particle wave function at this eigenstate shows that this peak is due to weak $\mathrm{N}-\mathrm{Cu}$ and strong $\mathrm{Cu}-\mathrm{Cu}$ bonding 


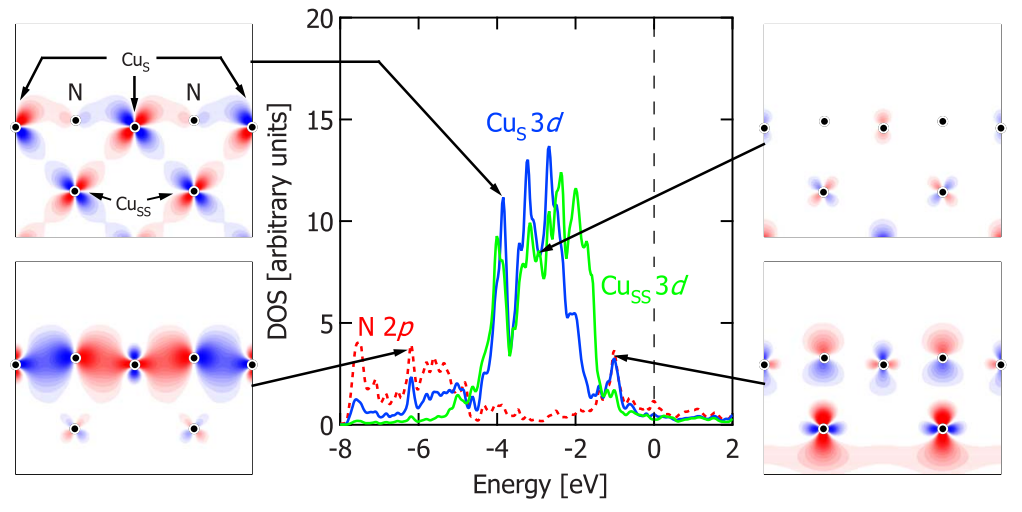

FIG. 5. (Color online) Projected density of states for the $\mathrm{Cu}(100)-c(2 \times 2)-\mathrm{N}$ structure. The dark, solid (blue) line represents the $3 d$ states of $\mathrm{Cu}$ atoms in the top-layer $\mathrm{Cu}$ (i.e., $\mathrm{Cu}_{\mathrm{S}}$ ) and the pale, solid (green) line represents the secondlayer $\mathrm{Cu}$ (i.e., $\mathrm{Cu}_{\mathrm{SS}}$ ) $3 d$ states, and the dotted (red) line represents N $2 p$ states. The insets (i.e., left and right panels) show the spatial distribution of the wave function at the $\Gamma$ point for the eigenstates indicated by the arrows. The positions of the atoms are indicated by small black dots and labeled accordingly. states. Other features of Fig. 5 include a higher occupancy of hybridized $\mathrm{N} 2 p$ and $\mathrm{Cu} 3 d$ bonding states, than antibonding states, suggesting a stronger $\mathrm{Cu}-\mathrm{N}$ bonding character in this structure than the cohesive energy of the metastable bulk nitride material (which is the case, i.e., of $-4.76 \mathrm{eV}$ versus $-4.03 \mathrm{eV}$ ). The nature of the states in the PDOS is confirmed by the single-particle wave functions at chosen eigenstates at the $\Gamma$ point, showing distinctly that the eigenvalues corresponding to low energies are due to bonding states, while those close to the Fermi level are due to antibonding states. Furthermore, the PDOS due to subsurface $\mathrm{Cu} 3 d$ states is broader than that due to $\mathrm{Cu} 3 d$ states from surface $\mathrm{Cu}$ atoms $\left(\mathrm{Cu}_{\mathrm{s}}\right)$, and this is due to reduced coordination at the surface of the latter. The location of the peaks of the $\mathrm{Cu}(100)-c(2 \times 2)-\mathrm{N}$ PDOS corresponds well with another theoretical result obtained by the full potential linearized muffin-tin orbital (FP-LMTO) method. ${ }^{61}$

Figure 6 displays the PDOS for the following surface nitride and $\mathrm{N} / \mathrm{Cu}(110)$ adsorption phases: $\mathrm{Cu}(110)-p(2$ $\times 3)-4 \mathrm{~N}, \mathrm{Cu}(110)-p(2 \times 3)-\mathrm{N}, \mathrm{Cu}(110)-p(2 \times 3)-2 \mathrm{~N}$, and $\mathrm{Cu}(110)-p(2 \times 4)-\mathrm{N}_{4 \mathrm{FH}}$ (i.e., with $\mathrm{N}$ at the $4 \mathrm{FH}$ site). We see that the PDOS can be roughly partitioned into three sections: from -8 to $-4 \mathrm{eV}$, bonding states between $\mathrm{N} 2 p$ and $\mathrm{Cu} 3 d$; from -4 to $-2 \mathrm{eV}$, dominantly $\mathrm{Cu} 3 d$ nonbonding states; and antibonding states between $\mathrm{N} 2 p$ and $\mathrm{Cu} 3 d$ at -2 to $2 \mathrm{eV}$ above the Fermi level. Similar to that seen in Fig. 5, there is a renormalization of the $\mathrm{N} 2 p$ energy levels to lower energies and a hybridization between $\mathrm{N} 2 p$ and $\mathrm{Cu} 3 d$ states in the region -8 to $-4 \mathrm{eV}$. However, for Figs. 6(d)-6(f), the hybridization of the bonding states is less pronounced (see between -7 and $-5 \mathrm{eV}$ ), thus reflecting a smaller binding energy than $\mathrm{Cu}(110)-p(2 \times 3)-4 \mathrm{~N}$. The $\mathrm{Cu} 3 d$ states in Figs. 6(b) and 6(c) indicate that subsurface $\mathrm{Cu}$ states $\left(\mathrm{Cu}_{\mathrm{ss}}\right)$ are broader than the surface $\mathrm{Cu}\left(\mathrm{Cu}_{\mathrm{s}}\right)$ states, and this is again due to reduced coordination of surface $\mathrm{Cu}$ atoms. It can be observed that the superposition of $\mathrm{Cu}_{\mathrm{s}}$ and $\mathrm{Cu}_{\mathrm{ss}}$ in Figs. 6(b)-6(f) leads to two dominant peaks, at energy values similar to the dominant peaks in the PDOS of $\mathrm{Cu}_{3} \mathrm{~N}$, at around -3.8 and $-2.5 \mathrm{eV}$ [see Fig. 9(a) in Ref. 39].

A comparison of the PDOS due to the $\mathrm{Cu}$ (111) " 16 " structure [see Figs. 9(b) and 9(c) in Ref. 39] with the PDOS for $\mathrm{Cu}(100)-c(2 \times 2)-\mathrm{N}$ and $\mathrm{Cu}(110)-p(2 \times 3)-4 \mathrm{~N}$ shows peaks in similar positions (at around -3.8, -2.5, and $-1.8 \mathrm{eV})$. The overall close resemblance of the PDOS for all the reconstructed models and the $\mathrm{Cu}(100)-c(2 \times 2)-\mathrm{N}$ structure to the bulk nitride is an indication that these surface nitrides and $\mathrm{N}$ chemisorption on $\mathrm{Cu}(100)$ could be a precursor phase before onset of the formation of the bulk material. For details of the PDOS of $\mathrm{N} / \mathrm{Cu}(111)$ structures and $\mathrm{Cu}_{3} \mathrm{~N}$, we refer the reader to Ref. 39.

\section{Relative stability and nanoparticle morphology}

In Fig. 7 we show the Gibbs-surface free energy of adsorption for the various structures considered. The nitrogen chemical potential at which bulk $\mathrm{Cu}_{3} \mathrm{~N}$ forms corresponds to the heat of formation of bulk $\mathrm{Cu}_{3} \mathrm{~N}$ (relative to the free $\mathrm{N}$ atom). The heat of formation of bulk $\mathrm{Cu}_{3} \mathrm{~N}$ per nitrogen atom is calculated as
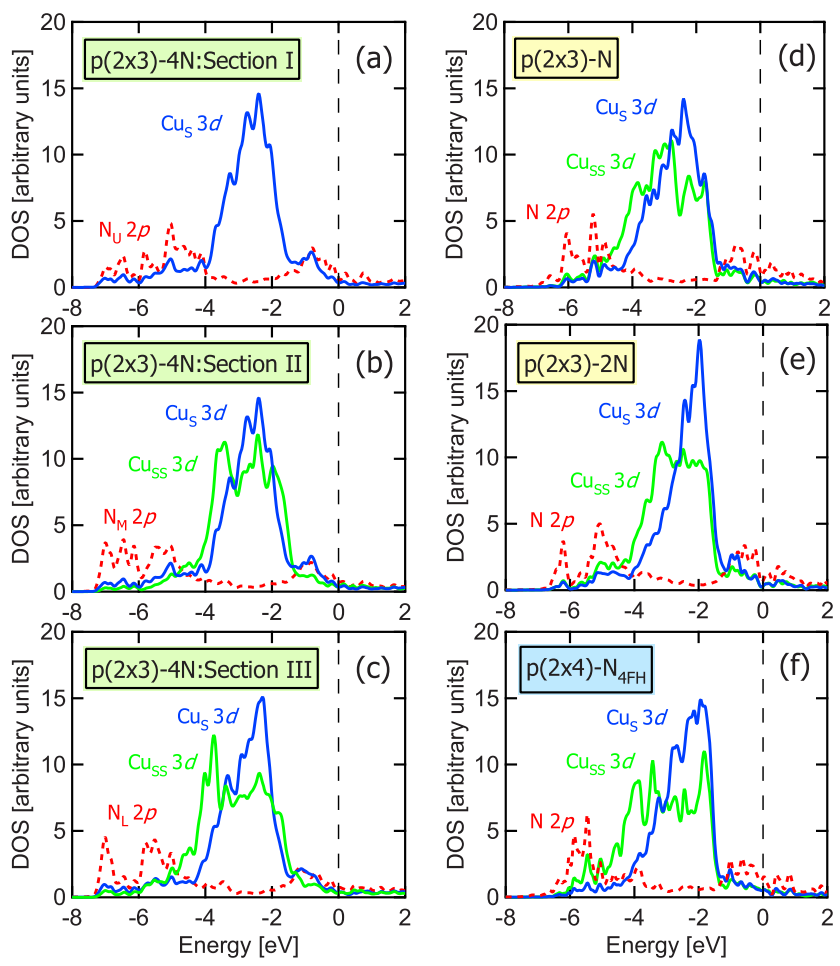

FIG. 6. (Color online) Projected density of states for selected low-energy $\mathrm{N} / \mathrm{Cu}(110)$ surface structures: $\mathrm{Cu}(110)-p(2 \times 3)-4 \mathrm{~N}$ for different sections [see Fig. 1(f)]: (a) section I, (b) section II, and (c) section III and (d) $\mathrm{Cu}(110)-p(2 \times 3)-\mathrm{N}$, (e) $\mathrm{Cu}(110)-p(2$ $\times 3)-2 \mathrm{~N}$, and (f) $\mathrm{Cu}(110)-p(2 \times 4)-\mathrm{N}_{4 \mathrm{FH}}$. The dark (blue) solid lines represent $\mathrm{Cu} 3 d$ states from surface $\mathrm{Cu}$ layer $\left(\mathrm{Cu}_{\mathrm{S}}\right)$, the lighter (green) solid lines represent second-layer $\mathrm{Cu}\left(\mathrm{Cu}_{\mathrm{SS}}\right) 3 d$ states, and the dotted dark (red) lines represent N $2 p$ states. 

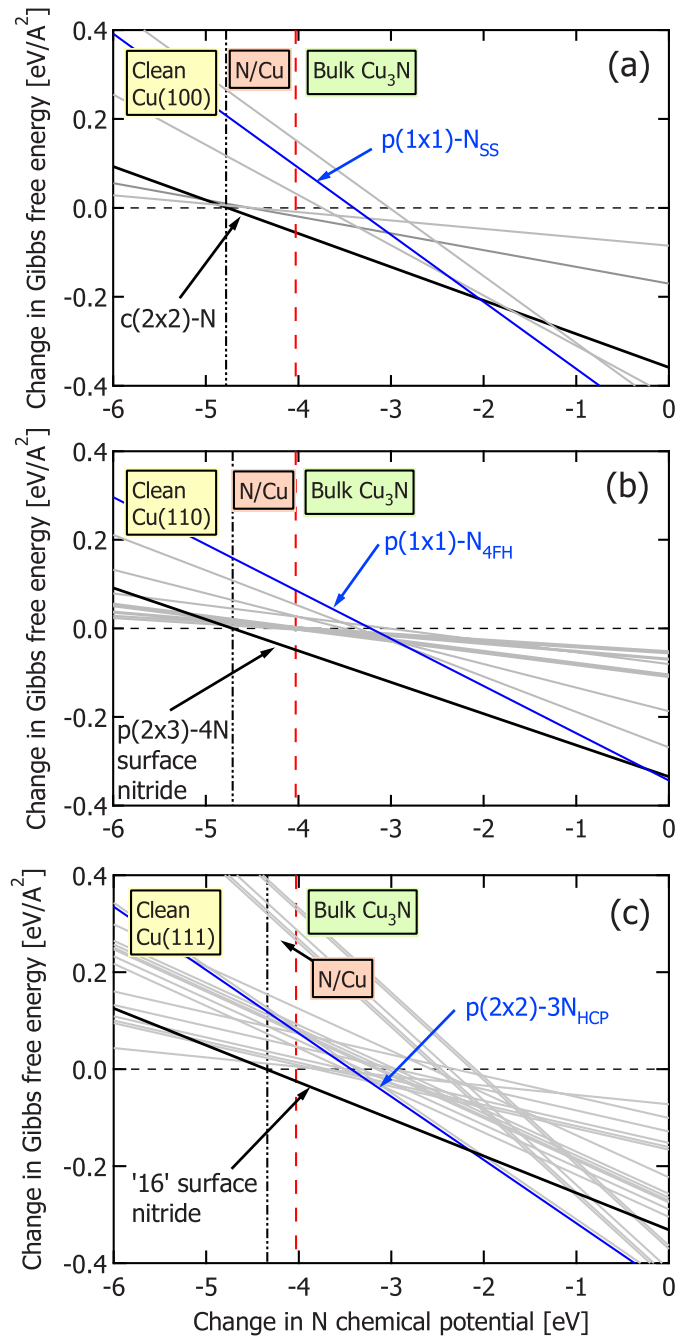

FIG. 7. (Color online) Calculated Gibbs-surface free energy of adsorption $\Delta G$, as a function of the change in $\mathrm{N}$ chemical potential, $\mu_{\mathrm{N}}$ for $\mathrm{Cu}$ (100), $\mathrm{Cu}$ (110), and $\mathrm{Cu}$ (111) substrates in (a), (b), and (c), respectively. The unfavorable adsorption phases are indicated in pale gray lines. The black lines indicate the $\mathrm{Cu}(100)-c(2 \times 2)-\mathrm{N}$ adsorption phase, the $\mathrm{Cu}(110)-p(2 \times 3)-4 \mathrm{~N}$ structure, and the "16" structure in (a), (b), and (c), respectively. The vertical, dashed dark (red) line indicates the heat of formation of bulk $\mathrm{Cu}_{3} \mathrm{~N}$ (with respect to atomic nitrogen), and the dot-dashed dark (black) vertical line indicates the chemical potential where the most favorable surface phase begins to form.

$$
\Delta H_{\mathrm{Cu}_{3} \mathrm{~N}}^{\mathrm{f}}=E_{\mathrm{Cu}_{3} \mathrm{~N}}-3 E_{\mathrm{Cu}}-E_{\mathrm{N}},
$$

where the total energies of bulk $\mathrm{Cu}_{3} \mathrm{~N}$, bulk $\mathrm{Cu}$, and the isolated $\mathrm{N}$ atom (calculated including spin-polarization) are represented by $E_{\mathrm{Cu}_{3} \mathrm{~N}}, E_{\mathrm{Cu}}$, and $E_{\mathrm{N}}$, respectively. The heat of formation is calculated with respect to atomic $\mathrm{N}$, to be consistent with experimental studies, ${ }^{10,20,25,32-38}$ in the sense that the adsorption phases are obtained by $\mathrm{N}$-ion bombardment. Using this equation, the obtained heat of formation is $-4.03 \mathrm{eV}$ and this is plotted in Fig. 7 as the rightmost vertical (red) dashed line.

For this study, it is difficult to determine which region of the chemical potential range the experimental studies fall into. As mentioned above, experimentally achieved $\mathrm{N}$ adsorption on $\mathrm{Cu}$ employs $\mathrm{N}$-ion bombardment of a $\mathrm{Cu}$ surface in an ultrahigh-vacuum (UHV) chamber, ${ }^{10,20,25,32-38}$ so there is no simple correlation between the chemical potential of nitrogen and other thermodynamic variables such as the temperature and pressure. This means that it is not straightforward to construct a two-dimensional phase diagram showing the equilibrium phase over regions in temperature-pressure space, as was done for the $\mathrm{O} / \mathrm{Cu}$ system. ${ }^{45}$ Nevertheless, we can only, at best, assume a "quasiequilibrium" state with atomic nitrogen and use it as a chemical reservoir, without relating the pressure-temperature effects via this chemical potential. In addition, the nitrogen atoms created in the experiments through ion bombardment and adsorbed at the surface of $\mathrm{Cu}$ would have to overcome a certain activation barrier to associatively desorb as $\mathrm{N}_{2}$. This is indeed why these so-called thermodynamically "metastable" structures are readily observed in experiments, even at moderate to slightly high temperatures. The $\mathrm{N} / \mathrm{Cu}$ (111) structures have been shown to be stable up to $500 \mathrm{~K},{ }^{37}$ and the $\mathrm{Cu}$ (110)-p(2 $\times 3)-4 \mathrm{~N}$ phase is also sufficiently stable enough to be removed from vacuum and then reinserted into the UHV chamber while retaining its $(2 \times 3)$ LEED pattern. ${ }^{6}$ Likewise, the $\mathrm{Cu}(100)-c(2 \times 2)-\mathrm{N}$ structures are just as stable up to 400 $\mathrm{K}{ }^{6}$ This clearly shows some form of kinetic hindering for the $\mathrm{N}$ atoms to recombine and desorb as $\mathrm{N}_{2}$. Hence, by simply considering the relationship between the change in Gibbs-surface free energy and the nitrogen-atom chemical potential, it nevertheless yields useful information regarding the relative stability of the various surface structures and how they might play a role in understanding thin-film growth mechanisms of $\mathrm{Cu}_{3} \mathrm{~N}$ (Refs. 62 and 63) and initial nitridation of copper.

From Fig. 7, it can be seen that at low $\mathrm{N}$ chemical potential, the clean surface is the preferred structure for all surface orientations. For $\mathrm{N}$ adsorption on $\mathrm{Cu}$ (100) [Fig. 7(a)], at $\Delta \mu_{\mathrm{N}}=-4.76 \mathrm{eV}$, the $\mathrm{Cu}(100)-c(2 \times 2)-\mathrm{N}$ phase becomes the most favorable structure for a narrow energy window, until the chemical potential reaches $-4.03 \mathrm{eV}$, where bulk copper nitride is preferred. From Fig. 7(b) it can be seen that the $\mathrm{Cu}(110)-p(2 \times 3)-4 \mathrm{~N}$ structure becomes more favorable than the clean $\mathrm{Cu}(110)$ surface at $\Delta \mu_{\mathrm{N}}=-4.71 \mathrm{eV}$, and thereafter the bulk phase is most favorable. For $\mathrm{N}$ on the $\mathrm{Cu}$ (111) surface, the "16" structure forms on $\mathrm{Cu}(111)$ at $\Delta \mu_{\mathrm{N}}$ $=-4.34 \mathrm{eV}$ [as seen in Fig. 7(c)] and then finally to the bulk copper nitride structure at $\Delta \mu_{\mathrm{N}}=-4.03 \mathrm{eV}$.

The shape of a $\mathrm{Cu}$ nanoparticle under various nitrogenatom chemical potentials can be determined using the Wulff construction, ${ }^{40}$ which yields an optimal crystal shape that minimizes the Gibbs-surface free energy (i.e., absolute Gibbs-surface free energy). Each facet consists of a surface adsorption phase, and the distance of the facet from the center of the crystal is determined by the surface energy of the adsorption phase. The Gibbs-surface free energy is calculated by

$$
\gamma=-\frac{N_{\mathrm{N}} E_{b}^{\mathrm{N}}}{2 A}-\frac{N_{\mathrm{N}} \Delta \mu_{\mathrm{N}}}{2 A}+\gamma_{\text {clean }},
$$

where $A$ is the surface area and $\gamma_{\text {clean }}$ is the surface free 

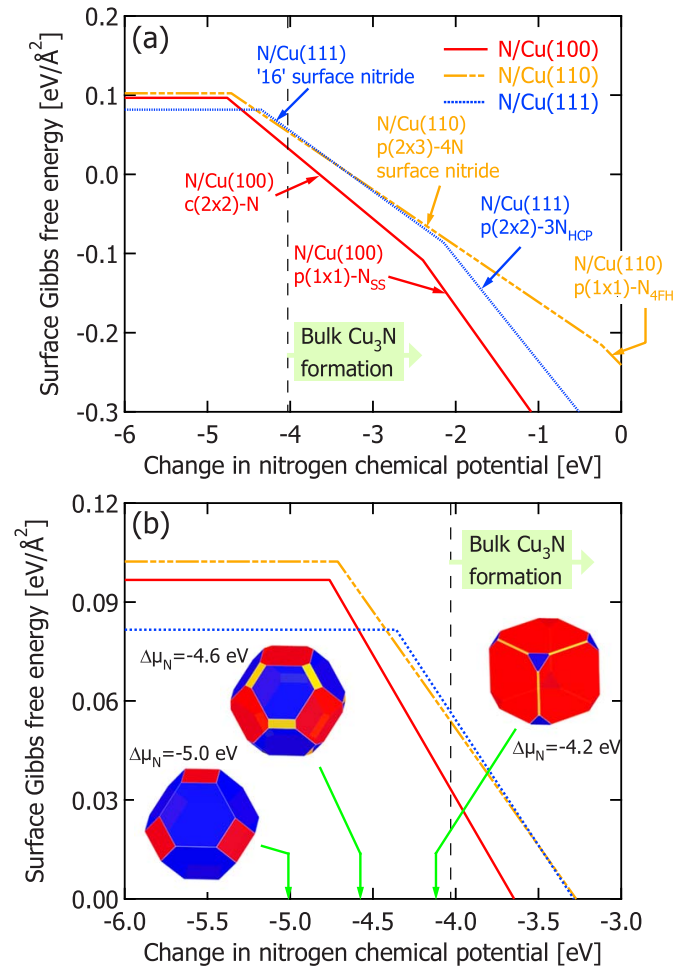

FIG. 8. (Color online) The surface free energy of the most favorable, adsorption structures considered on $\mathrm{Cu}$ (100), $\mathrm{Cu}$ (110), and $\mathrm{Cu}$ (111) is plotted in (a) as a function of the nitrogen-atom chemical potential $\mu_{\mathrm{N}}$. The horizontal lines at low $\mu_{\mathrm{N}}$ show the region where the clean $\mathrm{Cu}$ surfaces are the preferred structure. The bottom figure (b) is a magnification of the top figure (a), with insets depicting the predicted $\mathrm{Cu}$ nanoparticle shapes for selected values of $\mu_{\mathrm{N}}$.

energy of the clean substrate. The program WINXMORPH was used to plot the crystal nanomorphology. ${ }^{64,65}$

The results for all low-indexed orientations are shown in Fig. 8(a), as a function of the nitrogen-atom chemical potential $\Delta \mu_{\mathrm{N}}$. In Fig. $8(\mathrm{~b})$, we show the resulting particle nanomorphology for three selected values of $\Delta \mu_{\mathrm{N}}$. It can be seen that at low $\Delta \mu_{\mathrm{N}}$, the crystal shape is dominated by clean $\mathrm{Cu}$ (111) facets, which has the lowest Gibbs-surface free energy for this chemical potential region. As $\Delta \mu_{\mathrm{N}}$ is increased to the range where the $\mathrm{Cu}$ (110) surface nitride structure and the chemisorption phase of $\mathrm{N} / \mathrm{Cu}$ (100) form-for example, at $\Delta \mu_{\mathrm{N}}=-4.6 \mathrm{eV}$ - the crystal shape now consists of facets of $\mathrm{Cu}(100)-c(2 \times 2)-\mathrm{N}$, a small portion of $\mathrm{Cu}(110)-p(2$ $\times 3)-4 \mathrm{~N}$, and clean $\mathrm{Cu}(111)$ facets. However, as the potential is increased to $\Delta \mu_{\mathrm{N}}=-4.2 \mathrm{eV}$, the polyhedron consists almost entirely of the surface nitride phases on $\mathrm{Cu}$ (100), with small areas of N/Cu (110) and N/Cu (111): namely, the $\mathrm{Cu}(100)-c(2 \times 2)-\mathrm{N}, \quad \mathrm{Cu}(110)-p(2 \times 3)-4 \mathrm{~N}, \quad$ and $\mathrm{N} / \mathrm{Cu}$ (111) "16" structures. Beyond $\Delta \mu_{\mathrm{N}}=-4.03 \mathrm{eV}$, the bulk copper nitride structure forms and thus we expect the crystal would consist of surfaces of bulk $\mathrm{Cu}_{3} \mathrm{~N}$. The Wulff construction is clearly limited by the number of surfaces we have studied: inclusion of stepped surfaces, for example, may affect the predicted shape of the crystal. However, it is well known that the low-index faces are the most stable structures, ${ }^{66}$ so the basic predicted shape is not expected to change drastically.

\section{CONCLUSIONS}

We performed density-functional-theory calculations to investigate the adsorption of nitrogen on the $\mathrm{Cu}(100)$ and $\mathrm{Cu}$ (110) surfaces. For chemisorption of $\mathrm{N}$ on $\mathrm{Cu}$ (100), the preferred adsorption phase is the $0.5-\mathrm{ML} \mathrm{Cu}(100)-c(2$ $\times 2$ )-N structure, where adsorption is in the fourfold hollow sites, in agreement with experiment. For adsorption of $\mathrm{N}$ on $\mathrm{Cu}$ (110), in addition to adsorption on the unreconstructed substrate, various surface reconstructions, including a surface nitride reconstruction, were considered. The most stable adsorption phase was found to be the $\mathrm{Cu}(110)-p(2 \times 3)-4 \mathrm{~N}$ structure, where the surface reconstructs into a configuration which closely resembles that of a layer of bulk $\mathrm{Cu}_{3} \mathrm{~N}$. Using the Gibbs-surface free energy and including the results of our previous investigation into $\mathrm{N}$ adsorption on $\mathrm{Cu}(111),{ }^{39}$ we obtain the predicted $\mathrm{Cu}$ particle nanomorphology based on the Wulff construction. At low nitrogen chemical potential, the clean $\mathrm{Cu}$ (111) facets dominate the crystal shape, while just prior to the formation of bulk copper nitride surfaces, the $\mathrm{Cu}$ crystal is composed of only $\mathrm{Cu}(100)-c(2 \times 2)-\mathrm{N}$ and $\mathrm{Cu}(110)-p(2 \times 3)-4 \mathrm{~N}$ facets. Collectively, we find for all low-energy $\mathrm{N} / \mathrm{Cu}$ surface structures-namely, $\mathrm{Cu}(100)-c(2 \times 2)-\mathrm{N}$ and the surface nitrides found on $\mathrm{Cu}$ (110) and $\mathrm{Cu}(111)$ - that they share a common geometric feature with surface nanopatterns resembling one atomic layer of $\mathrm{Cu}_{3} \mathrm{~N}(100)$. These structures are predicted to exist for a narrow range of nitrogen chemical potential before the onset of bulk $\mathrm{Cu}_{3} \mathrm{~N}$ formation, unless kinetically hindered. These observations are qualitatively very similar to the surface oxides found on transition-metal surfaces in an oxygen atmosphere (see Ref. 44 and references therein).

\section{ACKNOWLEDGMENTS}

We gratefully acknowledge support from the Australian Research Council (ARC), the Australian Partnership for Advanced Computing (APAC) National Facility, and the Australian Centre for Advanced Computing and Communications (ac3).

\section{APPENDIX}

To test the accuracy of our calculated adsorption energies on a number of calculation parameters-namely, the realspace cutoff, the slab thickness, and the k-point grid to integrate the Brillouin zone-selected calculations have been repeated with higher accuracy. We find that none of these aspects qualitatively affect the conclusions made in this work as explained below.

First, for bulk $\mathrm{Cu}$, by varying the real-space cutoff from 9 (as used in our studies) to 11 bohrs, the calculated cohesive energy of bulk copper did not differ by more than $1 \mathrm{meV}$ per $\mathrm{Cu}$ atom. The same difference of $1 \mathrm{meV}$ per $\mathrm{Cu}$ atom was also found for the calculated cohesive energy of bulk $\mathrm{Cu}$ when varying the k-point grid from $8 \times 8 \times 8$ to $16 \times 16$ $\times 16$. This demonstrates that the chosen real-space cutoff gives a good description of the bulk properties of $\mathrm{Cu}$, which, is reported in detail in Ref. 45. 
Next, we have tested the convergence of our slab calculations by testing the change in surface energy, $\gamma_{\text {clean }}$ (in $\mathrm{eV} / \AA^{2}$ ), as a function of the k-point mesh. For example, in Table III, for $\mathrm{Cu}(100)$, increasing the k-point mesh from 8 $\times 8 \times 1$ to $14 \times 14 \times 1$ does not change the surface energy by more than $5 \mathrm{meV} / \AA^{2}$ and the interlayer relaxations change at most by $0.01 \%$. Increasing from $12 \times 12 \times 1$ (used in the present study) to $14 \times 14 \times 1$ changes the two properties by at most $1 \mathrm{meV} / \AA^{2}$ and $0 \%$.

For the $\mathrm{Cu}$ (110) surface, the change in surface energy and interlayer relaxations on increasing from $12 \times 6 \times 1$ (used in the present study) to $14 \times 12 \times 1$ are similarly at most $1 \mathrm{meV} / \AA^{2}$ and $0 \%$.
TABLE III. Comparison of surface energy $\gamma_{\text {clean }}\left(\right.$ in $\left.\mathrm{eV} / \AA^{2}\right)$ and interlayer distances-i.e., $\Delta_{12}$ and $\Delta_{23}$ (in \%) —as a function of the k-point mesh for the clean $\mathrm{Cu}(100)$ and $\mathrm{Cu}$ (110) surfaces.

\begin{tabular}{ccccc}
\hline \hline Surface & k-point mesh & $\gamma_{\text {clean }}$ & $\Delta_{12}$ & $\Delta_{23}$ \\
\hline $\mathrm{Cu}(100)$ & $8 \times 8 \times 1$ & 0.093 & -2.5 & 0.77 \\
& $12 \times 12 \times 1$ & 0.097 & -2.5 & 0.76 \\
& $14 \times 14 \times 1$ & 0.098 & -2.5 & 0.76 \\
$\mathrm{Cu}(110)$ & $6 \times 3 \times 1$ & 0.104 & -8.7 & 1.4 \\
& $12 \times 6 \times 1$ & 0.103 & -10.3 & 2.7 \\
& $12 \times 8 \times 1$ & 0.102 & -10.2 & 2.6 \\
& $14 \times 12 \times 1$ & 0.102 & -10.3 & 2.7 \\
\hline \hline
\end{tabular}

*Corresponding author: aloysius@physics.usyd.edu.au

${ }^{1}$ G. Centi and S. Perathoner, Appl. Catal. 132, 179 (1995).

${ }^{2}$ P. J. Godowski, J. Onsgaard, A. Gagor, M. Kondys, and Z. S. Li, Chem. Phys. Lett. 406, 441 (2005).

${ }^{3}$ M. Brandhorst, J. Zajac, D. J. Jones, J. Rozière, M. Womes, A. Jimenez-López, and E. Rodríguez-Castellón, Appl. Catal., B 55, 267 (2005).

${ }^{4}$ I. Louis-Rose, C. Méthivier, and C. Pradier, Catal. Today 85, 267 (2003).

${ }^{5}$ R. W. Mayer, M. Hävecker, A. Knop-Gericke, and R. Schlögl, Catal. Lett. 74, 115 (2001).

${ }^{6}$ F. M. Leibsle, Surf. Sci. 514, 33 (2002).

${ }^{7}$ T. E. Wofford, S. M. York, and F. M. Leibsle, Surf. Sci. 522, 47 (2003).

${ }^{8}$ T. E. Wofford, S. M. York, and F. M. Leibsle, Surf. Sci. 539, 186 (2003).

${ }^{9}$ S. M. Driver and D. P. Driver, Surf. Sci. 539, 182 (2003).

${ }^{10}$ S. M. Driver and D. P. Woodruff, Surf. Sci. 442, 1 (1999).

${ }^{11}$ S. M. Driver and D. P. Woodruff, Surf. Sci. 560, 35 (2004).

${ }^{12}$ C. Cohen, H. Ellmer, J. M. Guigner, A. L'Hoir, G. Prévot, and D. Schmaus, Surf. Sci. 490, 336 (2001).

${ }^{13}$ R. B. S. Schär, T. Eguchi, E. Gnecco, O. Pfeiffer, L. Nony, and E. Meyer, Appl. Surf. Sci. 210, 43 (2003).

${ }^{14}$ H. C. Zeng, R. N. S. Sodhi, and K. A. R. Mitchell, Surf. Sci. 188, 599 (1987)

${ }^{15}$ H. C. Zeng and K. A. R. Mitchell, Langmuir 5, 829 (1989).

${ }^{16}$ F. Komori, S. Ohno, and K. Nakatsuji, Prog. Surf. Sci. 77, 1 (2004).

${ }^{17}$ X. M. Tao, M. Q. Tan, X. X. Zhao, W. B. Chen, X. Chen, and X. F. Shang, Surf. Sci. 600, 3419 (2006).

${ }^{18}$ Y. Yoshimoto and S. Tsuneyuki, Surf. Sci. 514, 200 (2002).

${ }^{19}$ H. Ellmer, V. Repain, S. Rousset, B. Croset, M. Sotto, and P. Zeppenfeld, Surf. Sci. 476, 95 (2001).

${ }^{20}$ S. M. Driver and D. P. Woodruff, Surf. Sci. 492, 11 (2001).

${ }^{21}$ M. Sotto and B. Croset, Surf. Sci. 461, 78 (2000).

${ }^{22}$ M. Sotto, S. Gauthier, F. Pourmir, S. Rousset, and J. Klein, Surf. Sci. 371, 36 (1997).

${ }^{23}$ D. T. Vu and K. A. R. Mitchell, Phys. Rev. B 49, 11515 (1994).

${ }^{24}$ S. Moré, W. Berndt, C. Stampfl, and A. M. Bradshaw, Surf. Sci. 381, L589 (1997).
${ }^{25}$ M. J. Ashwin and D. P. Woodruff, Surf. Sci. 237, 108 (1990).

${ }^{26}$ A. W. Robinson, D. P. Woodruff, J. S. Somers, A. L. D. Kilcoyne, D. E. Ricken, and A. M. Bradshaw, Surf. Sci. 237, 99 (1990).

${ }^{27}$ L. Wilde, N. Pangher, and J. Haase, Surf. Sci. 347, 33 (1996).

${ }^{28}$ H. Wende, D. Arvanitis, M. Tischer, R. Chauvistré, H. Henneken, F. May, and K. Baberschke, Phys. Rev. B 54, 5920 (1996).

${ }^{29}$ A. P. Baddorf, D. M. Zehner, G. Helgesen, D. Gibbs, A. R. Sandy, and S. G. J. Mochrie, Phys. Rev. B 48, 9013 (1993).

${ }^{30}$ D. T. Vu Grimsby, M. Y. Zhou, and K. A. R. Mitchell, Surf. Sci. 271, 519 (1992).

${ }^{31}$ H. Niehus, R. Spitzl, K. Besocke, and G. Comsa, Phys. Rev. B 43, 12619 (1991).

${ }^{32}$ V. Higgs, P. Hollins, M. E. Pemble, and J. Pritchard, J. Electron Spectrosc. Relat. Phenom. 39, 137 (1986).

${ }^{33}$ J. F. Skelly, T. Bertrams, A. W. Munz, M. J. Murphy, and A. Hodgson, Surf. Sci. 415, 48 (1998).

${ }^{34}$ M. A. Muñoz-Márquez, G. S. Parkinson, P. D. Quinn, M. J. Gladys, R. E. Tanner, D. P. Woodruff, T. C. Q. Noakes, and P. Bailey, Surf. Sci. 582, 97 (2005).

${ }^{35}$ R. L. Toomes, J. Robinson, S. M. Driver, D. P. Woodruff, P. Baumgärtel, T. Geißel, R. Lindsay, O. Schaff, and A. M. Bradshaw, J. Phys.: Condens. Matter 12, 3981 (2000).

${ }^{36}$ S. M. Driver, J. T. Hoeft, M. Polcik, M. Kittel, R. Terborg, R. L. Toomes, J. H. Kang, and D. P. Woodruff, J. Phys.: Condens. Matter 13, L601 (2001).

${ }^{37}$ A. M. Goedken, S. L. Silva, S. M. York, and F. M. Leibsle, Eur. Phys. J. A 19, 77 (2002).

${ }^{38}$ D. P. Woodruff, J. Phys.: Condens. Matter 6, 6067 (1994).

${ }^{39}$ A. Soon, L. Wong, M. Lee, M. Todorova, B. Delley, and C. Stampfl, Surf. Sci. 601, 4775 (2007).

${ }^{40}$ G. Wulff, Z. Kristallogr. 34, 449 (1901).

${ }^{41}$ J. P. Perdew, K. Burke, and M. Ernzerhof, Phys. Rev. Lett. 77, 3865 (1996).

${ }^{42}$ B. Delley, J. Chem. Phys. 92, 508 (1990).

${ }^{43}$ B. Delley, J. Chem. Phys. 113, 7756 (2000).

${ }^{44}$ K. Reuter, C. Stampfl, and M. Scheffler, Handbook of Materials Modeling (Springer, Berlin, 2005), Vol. 1.

${ }^{45}$ A. Soon, M. Todorova, B. Delley, and C. Stampfl, Phys. Rev. B 
73, 165424 (2006).

${ }^{46}$ C. Kittel, Introduction to Solid State Physics (Wiley, New York, 1996).

${ }^{47}$ W. X. Li, C. Stampfl, and M. Scheffler, Phys. Rev. B 65, 075407 (2002).

${ }^{48}$ M. Todorova, K. Reuter, and M. Scheffler, J. Phys. Chem. B 108, 14477 (2004).

${ }^{49}$ M. V. Ganduglia-Pirovano and M. Scheffler, Phys. Rev. B 59, 15533 (1999).

${ }^{50}$ R. Mayer, C. S. Zhang, K. G. Lynn, W. E. Frieze, F. Jona, and P. M. Marcus, Phys. Rev. B 35, 3102 (1987).

${ }^{51}$ J. Wan, Y. L. Fan, D. W. Gong, S. G. Shen, and X. Q. Fan, Modell. Simul. Mater. Sci. Eng. 7, 189 (1999).

${ }^{52}$ P. O. Gartland, S. Berge, and B. J. Slagsvold, Phys. Rev. Lett. 28, 738 (1972)

${ }^{53}$ J. L. F. Da Silva, C. Stampfl, and M. Scheffler, Surf. Sci. 600, 703 (2006).

${ }^{54}$ J. L. F. Da Silva, C. Barreteau, K. Schroeder, and S. Blügel, Phys. Rev. B 73, 125402 (2006).
${ }^{55}$ H. P. Bonzel and M. Nowicki, Phys. Rev. B 70, 245430 (2004).

${ }^{56}$ H. L. Davis and J. R. Noonan, Surf. Sci. 126, 245 (1983).

${ }^{57}$ J. L. F. Da Silva, K. Schroeder, and S. Blügel, Phys. Rev. B 69, 245411 (2004).

${ }^{58}$ H. L. Skriver and N. M. Rosengaard, Phys. Rev. B 46, 7157 (1992).

${ }^{59}$ CRC Handbook of Chemistry and Physics, 87th ed., edited by D. R. Lide (CRC Press, Boca Raton, 2007).

${ }^{60}$ T. Lederer, D. Arvanitis, M. Tischer, G. Comelli, L. Tröger, and K. Baberschke, Phys. Rev. B 48, 11277 (1993).

${ }^{61}$ T. Wiell, J. E. Klepeis, P. Bennich, O. Björneholm, N. Wassdahl, and A. Nilsson, Phys. Rev. B 58, 1655 (1998).

${ }^{62}$ Y. Du, A. L. Ji, L. B. Ma, Y. Q. Wang, and Z. X. Cao, J. Cryst. Growth 280, 490 (2005).

${ }^{63}$ G. H. Yue, P. X. Yan, and J. Wang, J. Cryst. Growth 274, 464 (2005).

${ }^{64}$ W. Kaminsky, J. Appl. Crystallogr. 38, 566 (2005).

${ }^{65}$ W. Kaminsky, J. Appl. Crystallogr. 40, 382 (2007).

${ }^{66}$ L. D. Marks, Rep. Prog. Phys. 57, 603 (1994). 